AWARD NUMBER: W81XWH-13-1-0290

TITLE: Targeting the Prometastatic Microenvironment of the Involuting Mammary Gland

PRINCIPAL INVESTIGATOR: Pamela Cowin, Ph.D.

CONTRACTING ORGANIZATION: New York University

New York, NY 10016

REPORT DATE: September 2014

TYPE OF REPORT: Annual Report

PREPARED FOR: U.S. Army Medical Research and Materiel Command

Fort Detrick, Maryland 21702-5012

DISTRIBUTION STATEMENT: Approved for Public Release;

Distribution Unlimited

The views, opinions and/or findings contained in this report are those of the author(s) and should not be construed as an official Department of the Army position, policy or decision unless so designated by other documentation. 


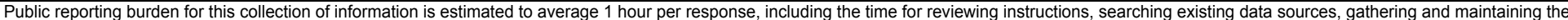

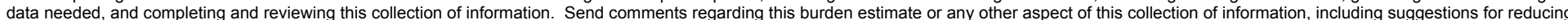

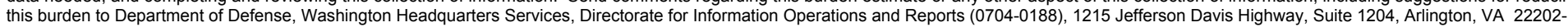

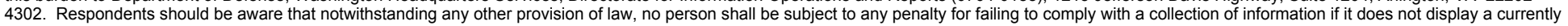
valid OMB control number. PLEASE DO NOT RETURN YOUR FORM TO THE ABOVE ADDRESS.
1. REPORT DATE
4FQUFNCFS 2014

4. TITLE AND SUBTITLE

Targeting the Prometastatic Microenvironment of the Involuting

Mammary Gland
3. DATES COVERED

1 Sept 2013 - 31 Aug 2014

5a. CONTRACT NUMBER

5b. GRANT NUMBER

W81XWH-13-1-0290

5c. PROGRAM ELEMENT NUMBER

5d. PROJECT NUMBER

6. AUTHOR(S)

Cowin, Pamela

5e. TASK NUMBER

5f. WORK UNIT NUMBER

8. PERFORMING ORGANIZATION REPORT NUMBER

E-Mail: cowinp01@nyumc.org

7. PERFORMING ORGANIZATION NAME(S) AND ADDRESS(ES)

NEW YORK UNIVERSITY

New York, NY 10016

10. SPONSOR/MONITOR'S ACRONYM(S)

9. SPONSORING / MONITORING AGENCY NAME(S) AND ADDRESS(ES)

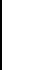

U.S. Army Medical Research and Materiel Command

Fort Detrick, Maryland 21702-5012

11. SPONSOR/MONITOR'S REPORT

NUMBER(S)

\section{DISTRIBUTION / AVAILABILITY STATEMENT}

Approved for Public Release; Distribution Unlimited

\section{SUPPLEMENTARY NOTES}

\section{ABSTRACT}

We hypothesized that Latent TGFbeta Binding Protein 1 (LTBP1) expression creates a pro-metastatic environment. We proposed three aims to test this hypothesis 1) Determine the utility of LTBP1 expression as a biomarker in human breast cancer 2) Determine the consequences of modulating LTBP1 levels on cell motility, invasion and metastasis in human and murine breast cell lines 3 ) Investigate the pathological significance of gain and loss of LTBP1 in genetically engineered mouse models. Our most important findings in this cycle are that LTBP1 expression is robustly elevated during involution, a window of development associated with heightened risk of highly metastatic breast cancer, that high LTBP1 expression occurs in luminal HER2-positive and basal breast cancers and expression level within these subgroups correlates with poor outcome. This was achieved by determining the expression pattern of LTBP1 in LTBP1-lacZ reporter mice, by qPCR and immunofluorescence over the entire course of mammary development in mice and by bioinformatically mining databases of human breast cancer. During this period we have also validated antibodies, screened breast cancer lines for LTBP1 expression and developed lentiviral expression tools that will enable us to proceed to test the effects of modulating LTBP levels on cell migration.

\section{SUBJECT TERMS}

Cell Adhesion, Involution, Metastasis, Latent TGFbeta Binding Protein, Pregnancy-associated Breast Cancer

\begin{tabular}{|l|l|l|l|l|l|}
\hline \multicolumn{2}{|l|}{ 16. SECURITY CLASSIFICATION OF: U } & $\begin{array}{l}\text { 17. LIMITATION } \\
\text { OF ABSTRACT }\end{array}$ & $\begin{array}{l}\text { 18. NUMBER } \\
\text { OF PAGES }\end{array}$ & $\begin{array}{l}\text { 19a. NAME OF RESPONSIBLE PERSON } \\
\text { USAMRMC }\end{array}$ \\
\cline { 1 - 2 } & a. REPORT & c. THIS PAGE & UU & 31 & $\begin{array}{l}\text { 19b. TELEPHONE NUMBER (include area } \\
\text { code) }\end{array}$ \\
$\mathrm{U}$ & $\mathrm{U}$ & $\mathrm{U}$ & & \\
\hline
\end{tabular}




\section{Table of Contents}

\section{Page}

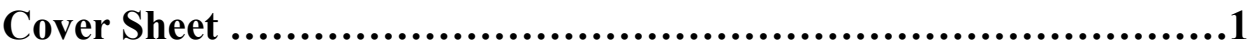

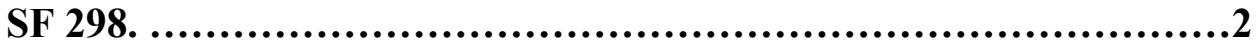

Table of Contents.....................................................3

1. Introduction...........................................................4

2. Keywords.............................................................4

3. Accomplishments....................................................4-10

4. Impact..............................................................11

5. Changes/Problems....................................................11

6. Products..........................................................11-12

7. Participants/Collaborators..........................................12-13

8. Special Reporting Requirements....................................13

9. Appendices..........................................................14-31 
1. INTRODUCTION: Latent TGFbeta binding protein plays a critical role in positioning and activating TGFbeta, a protein with dual tumor suppressor and promoter functions at different stages of breast cancer. Latent TGFbeta is secreted into the extracellular matrix bound to LTBP, which then associates with fibronectin and fibrillin associated with elastin fibers. LTBP1 has not been studied in the mammary gland or breast cancer. The goal of this proposal is to test whether elevated LTBP1 expression induces metastasis. This hypothesis was formulated based on our data showing that LTBP1 is highly expressed during normal involution, a window of development associated with heightened risk of breast cancer and is elevated in signatures of cell lines selected for specific sites of metastasis. The Aims of this project are to examine LTBP1 expression in breast cancer and to test functionally the effect of modulating LTBP1 on breast cancer cell line behavior and in mouse models of breast cancer.

2. KEYWORDS: Cell-matrix Adhesion, Involution, Metastasis, Latent TGFbeta Binding Protein, Pregnancy-associated Breast Cancer

\section{ACCOMPLISHMENTS:}

\section{What were the major goals of the project:}

Task 1) Determine the utility of LTBP1 expression as a biomarker in human breast cancer. ( $25 \%$ complete)

Task 2) Determine the consequences of modulating LTBP1 levels on cell motility, invasion and metastasis in human and murine breast cell lines. (30\% complete)

Task 3) Determine the pathological significance of gain and loss of LTBP1 in genetically engineered mouse models. ( $25 \%$ complete)

\section{What was accomplished under these goals:}

\section{a) Completion of preliminary data:}

During this reporting period we completed, submitted, revised and published the data that contributed to the preliminary data of our proposal. This data is appended in the attached published manuscript Chandramouli et al. This comprised establishing the expression pattern of the LTBP1 promoter using an LTBP1-lacZ reporter mouse over the entire course of embryonic (Figures 2, 3, $4 \mathrm{a}, \mathrm{b}$ and 6), nipple (Figures $4 \mathrm{c}, \mathrm{d}$ and 5) and adult (Figures $7 \mathrm{c}$ and $\mathrm{d}, 8,9,10)$ mammary development, examining mRNA expression of both LTBP1 isoforms by qPCR (Figures. 7a, b) and localizing the secreted LTBP1 protein by immunofluorescence to the ductal encasement (Figures10 $\mathrm{g}$ and $\mathrm{h}, 11$ ). The key findings of this study are that LTBP1 is dynamically regulated and will restrict TGFbeta activity to specific periductal locations and windows of development. We show that LTBP1 expression correlates with lumen formation and the emergence of the luminal cell fate. Importantly, it is produced exclusively by a subset of luminal cells (Figure 7 c-f) restricted to the permanent ductal system and provides a rare unique marker distinguishing ductal from alveolar luminal lineages. LTBP1 protein was found exclusively encasing the ductal system and is absent from terminal end buds and alveoli. The permanent ductal system, which harbors mammary stem cells, is encased by LTBP1 and elastin. In contrast the temporary mammary side branches are surrounded by LTBP1 but not elastin and alveoli lack both. Thus distinct segments of the mammary tree of 
differing function, fate and differentiation, stem cell content and longevity are associated with unique extracellular matrices. Importantly for this proposal we identified that LTBP1 mRNA and protein expression is maximal during involution. This developmental period involves the removal of temporary alveoli and side-branches following weaning and is associated with heightened breast cancer risk that is postulated to arise from the accompanying extensive matrix remodeling changes, which create a prometastatic microenvironment.

\section{b) Task 1. Determine the expression of LTBP1 in human and mouse breast cancers and breast cancer cell lines ( $25 \%$ complete)}

Luminal and basal breast cancer are both thought to arise from different types of luminal cells. Our preliminary and now published data, described above, show that ductal luminal cells produce LTBP. The significance of this for breast cancer is that it suggests that contrary to expectation, the seed of breast cancer produces and carries its own putative prometastatic soil.

The goal of Task 1 is to document LTBP1 expression in breast cancers and cell lines and correlate this with patient outcome. We proposed to examine a large number of human breast tumors, pregnancy associated breast cancers and a panel of breast cancer cell lines representative of the five major subtypes of human breast cancer.

To test our central hypothesis that increased LTBP1 is prometastatic we performed in silico analyses. To assess expression of Ltbp1 in breast cancer we began by mining in silico data using database available online specifically Kaplan-Meier plotter (kmplot.com), Breastmark (http://glados.ucd.ie/BreastMark/index.html) and Oncomine (www.oncomine.org) databases. High and low expression of Ltbp1 in total breast cancers and the different subtypes was correlated with Recurrence-Free and Distant Metastasis-Free Survival. High Ltbp1 was associated with poor survival outcomes using these datasets.

Recurrence-free survival

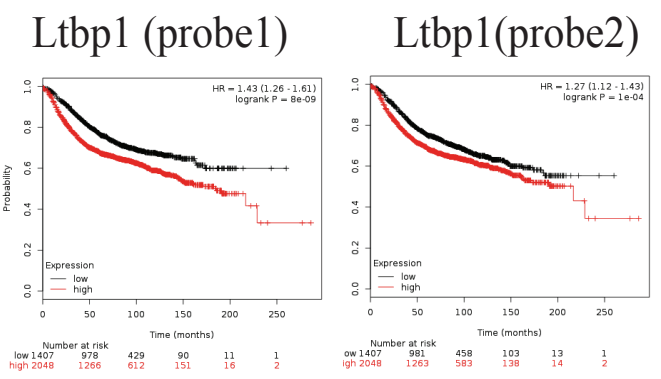

Distant metastatsis-free survival

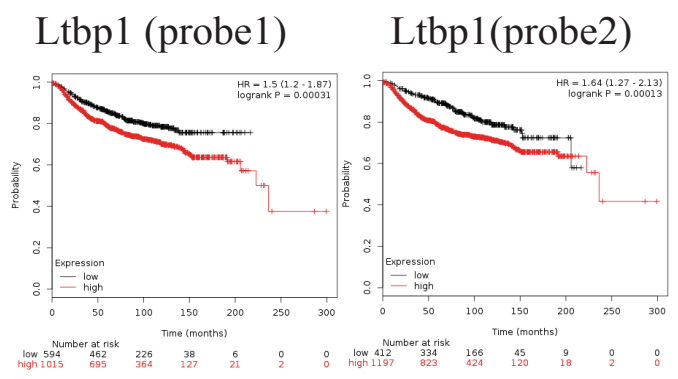

Figure 1: Recurrence-free survival and Distant metastasis-free survival is plotted for patient samples showing high LTBP1 expression (red) and lower expression (black) as assessed using Kaplan-Meier plotter. These data indicate a correlation between elevated LTBP1 expression and poor outcome. 
To provide a basis from which to select the human breast cancers that we should focus on for our studies of LTBP1 we analyzed the outcome data broken down into the major subtypes of breast cancer. This analysis shows that high LTBP1 expression correlated significantly with recurrence in Basal and HER2 subtypes and showed only a modest difference in luminal A and B subtypes.
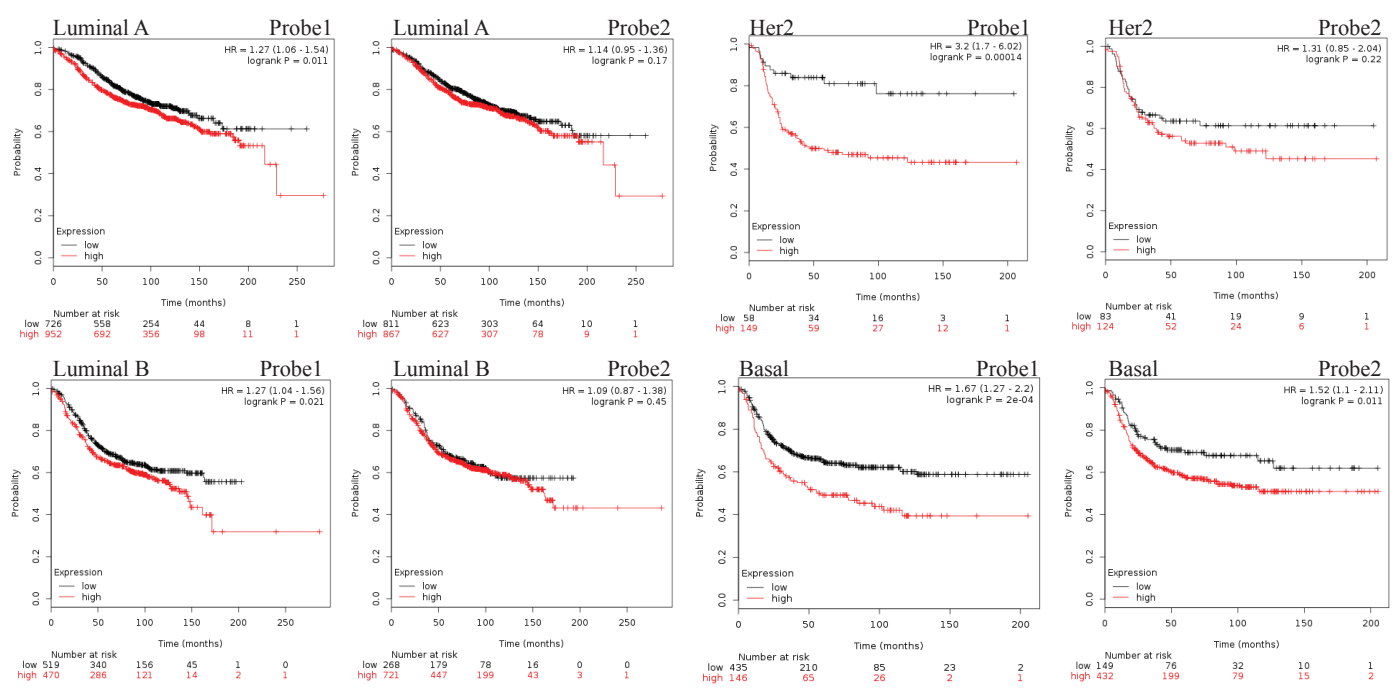

Figure 2: Shows Recurrence-free survival plotted for patient samples showing high LTBP1 expression (red) and lower expression (black) as assessed using Kaplan-Meier plotter. These data indicate a correlation between elevated LTBP1 expression and poor outcome within the HER2 and Basal type breast cancers.

We analyzed a panel of breast cancer cell lines for LTBP1 mRNA levels. Higher expression was seen in Basal B (Hs578t and MDA-MB-231) and Luminal HER2-positive ER-negative cell lines (AU565 and SkBr3) as compared to other Luminal and Basal A cell lines.

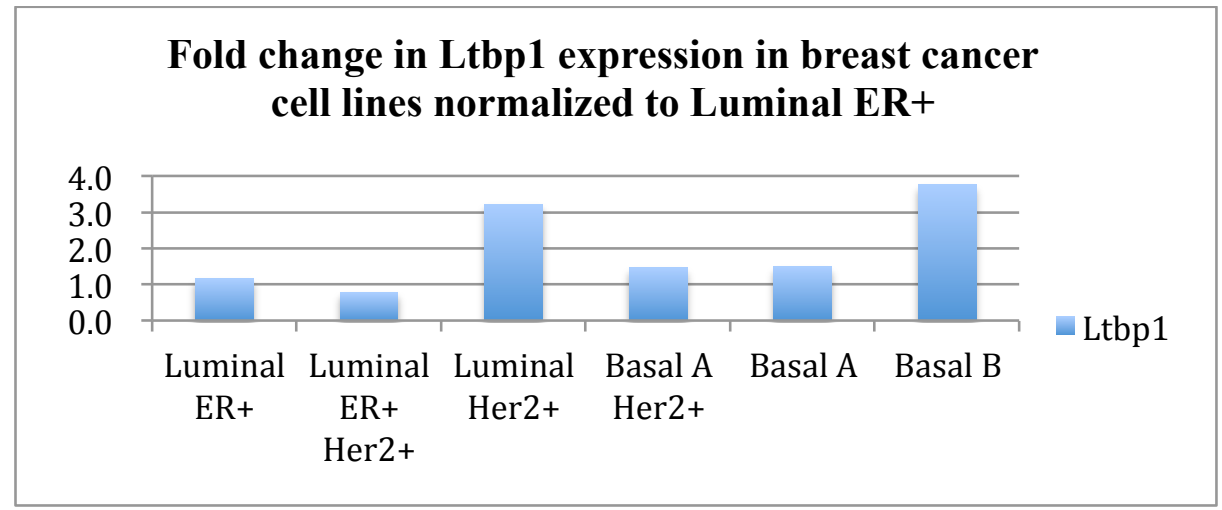

Figure 3: Cell lines were grouped into subtypes as classified by Neve et al. Their expression of LTBP1 expression was determined by qPCR normalized to levels found in Luminal cell lines and averaged for each cancer subtype.

Collectively these studies suggest that LTBP1 expression is most clinically relevant within the pathological setting of Basal and Luminal Her2-positive ER-negative breast 
cancers. These represent the breast cancers with the worst outcome and in the case of Basal breast cancer are the ones that are prevalent in young women of reproductive age.

In light of the findings above we plan to focus our efforts to detect LTBP1 expression on human Basal and Luminal HER2-positive ER-negative breast cancers and cell lines. In order to proceed with our plan to investigate LTBP1 protein expression and localization immunochemically in tissue microarrays of relevant human breast cancer samples it was necessary first to determine whether the available antibodies could detect human LTBP1 and to establish the conditions under which they work best. We have tested two antibodies, Ab39 and LIC, on frozen and paraffin embedded PFA-fixed normal breast samples derived from discarded reduction mammoplasty. We concurrently investigated the binding partner for LTBP1 by performing co-immunofluorescence for fibrillin 1 and elastin. Both antibodies localized LTBP1 in close proximity to the basal layer of human TDLU, similar to our findings in mice of LTBP1 encasing the mammary ducts. Both LTBP1 antibodies worked best on frozen sections. Elastin antibodies proved to be specific for mouse and did not stain human tissue, however elastin can be detected by histochemical stains as shown in figure 10 of our published paper. The fibrillin antibody worked well on human tissues specimens and showed robust expression next to the LTBP staining. Diffuse staining was observed with the LTBP1 antibodies on formalin-fixed and paraffin-embedded specimens. We are currently working on optimizing conditions that will permit reliable LTBP1 epitope retrieval in these samples as this will greatly facilitate the planned analysis of archival breast cancer specimens. In the meantime, we have requested the NYU biorepository core to retrieve and collect frozen and fixed samples of pregnancy associated breast cancer (see letter). We have also requested developmental stages of normal human breast development from the Susan G. Komen bank. These samples will allow us to confirm if elevated expression of LTBP1 occurs, as predicted form mouse studies, during normal involution and in PABC.

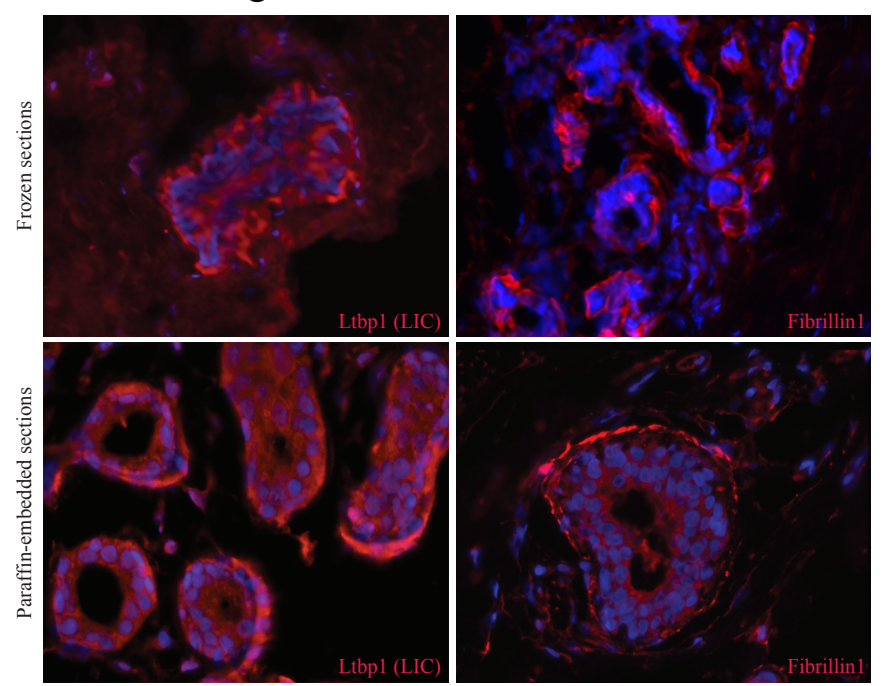

Figure 4: Immunofluorescent detection of LTBP1 with LIC antibody (left panels) and Fibrillin (right panels) in frozen (Top) and formalin-fixed paraffin embedded (bottom) sections 
Task 2 Determine the consequences on motility, invasion and metastasis of modulating LTBP1 level in breast cancer cell lines ( $30 \%$ complete).

Task 2a) Clone LTBP1 sequences into an appropriate expression vector, transfect human and mouse cell lines and assess LTBP1 expression by western analysis (months 10-18).

We have generated a cDNA of human LTBP1L and chosen to clone this into the lentiviral expression vector pHIV-Zsgreen, which has been successfully used to efficiently infect primary mammary epithelial cells as evidenced by GFP reporter expression. LTBP1 is a secreted protein, therefore to evaluate the extent of LTBP1 expression we have been optimizing LTBP1 detection within the conditioned media of breast cancer cell lines. As the antibodies recognize conformation-specific epitopes this requires SDS-PAGE analysis under non-reducing conditions. We now have these conditions established and are positioned to proceed to analyze the LTBP1-GFP-positive infected cell lines for their relative levels of secretion of LTBP.
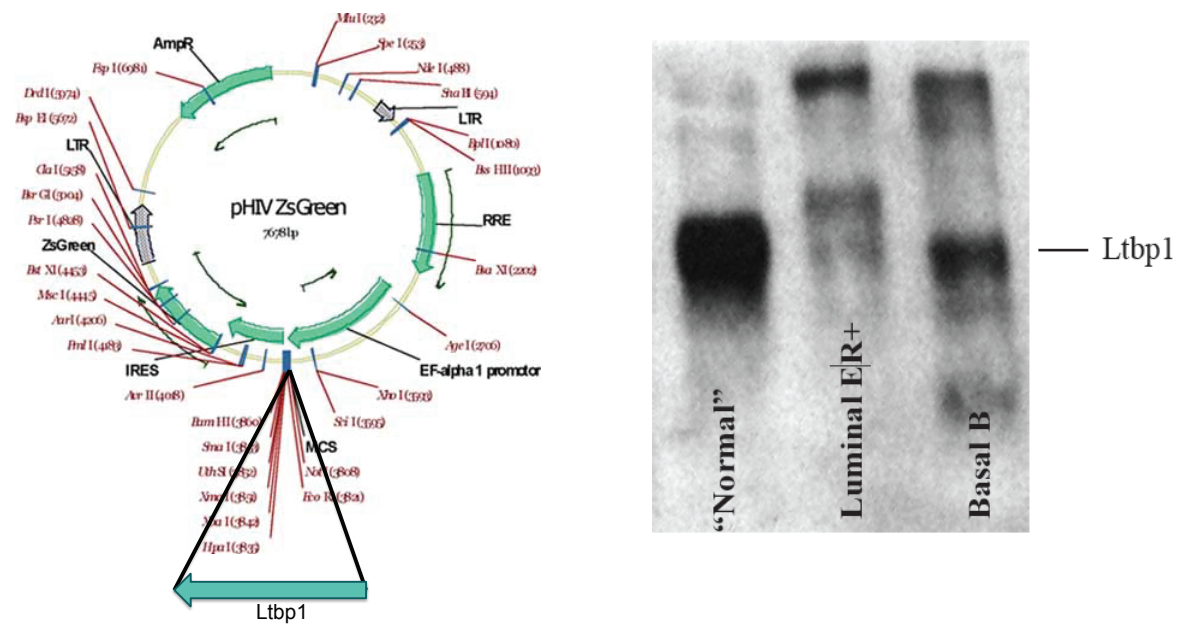

Figure 5: Shows the pHIV-LTBP1-ZsGreen expression construct (left) and detection of LTBP1 in the conditioned medium of breast cancer cell lines by western blotting under non-reducing SDS-PAGE conditions.

Task 2b) Clone short hairpin sequences of LTBP1 (shRNA) in lentiviral vectors, transfect into high LTBP1 expressing human (MDA-MB-231) and mouse (4T1) metastatic breast cell lines, and assess effective suppression by western analysis (months 10-18)

We have cloned two LTBP1 hairpins (sh1 within the coding region, sh2 in the 3'UTR and scrambled controls) into the lentiviral vector pLKO-GFP and pLKO-RFP respectively. We have tested their expression in the pLKO-GFP/RFP versions in MCF10A cells, which express LTBP1 robustly and found $75 \%$ infection rate as judged by reporter fluorescence (Figure 6 top panels). Both hairpins efficiently knocked down LTBP1 mRNA as assessed by RT-PCR (Figure 6 bottom panels). We are currently testing the specificity of this shRNA knock down and controlling for off-target effects by rescuing LTBP1 mRNA expression by co-expression of human LTBP1 lacking the 
3'UTR and pHIV-LTBP1-ZsGreen described above. Our next step will be to confirm this knock down at the protein level by western analysis. Once validated we aim next to infect the MDA-MB-231 and their more highly metastatic variant cells, which we have recently purchased from Dr. Juan Massague (MSKCC).

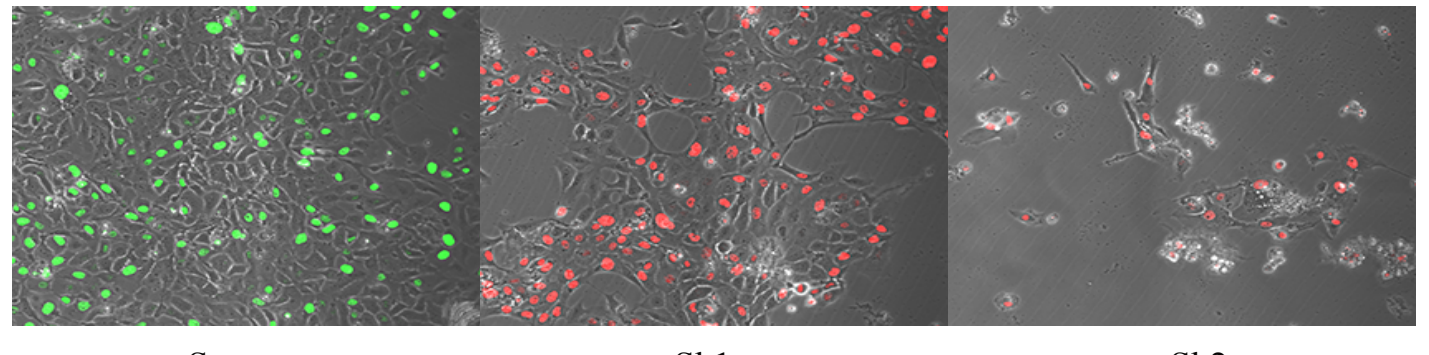

Scr

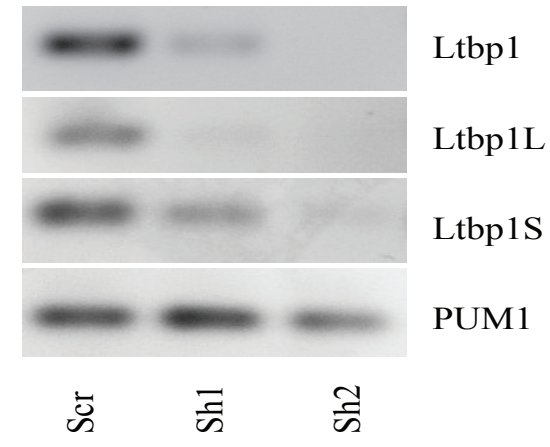

Sh1

Sh2

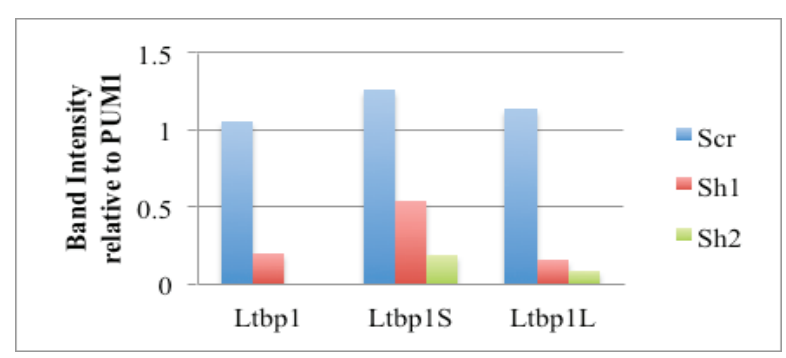

Figure 6: Top panel- MCF10A cells lentivirally infected with control scrambled shRNA hairpin (Scr) or LTBP1 shRNA hairpin (Sh1 and sh2). Note that sh2 induces cel rounding and detachment. Bottom left panel shows RT-PCR detection of LTBP1 expression in control (Scr) infected cells and efficient knock down of LTBP1L by sh1 and both isoforms of LTBP1 by sh2. Detection of PUM1 provides the internal control. Bottom right panel shows the data for LTBP1 mRNA expression normalized to expression of control PUM1.

Of note we have observed significant rounding and detachment of cells with strong reduction of both isoforms of LTBP1. This maybe biologically important and suggest a more fundamental role for LTBP1 in cell-matrix attachment. To explore the effects of LTBP1 knock down in a more quantitative way we have cloned both hairpins into a Tetracycline-regulatable form of the vector pLKO-Tet-On.

Task 3: Determine the pathological significance of gain and loss of LTBP1 in mice ( $25 \%$ complete).

\section{a) Generate the Ltbp1 transgenic mouse model (months 1-24)}

So far we have cloned the MMTV-LTR into pGEM5z and introduced a cassette comprising the rabbit beta-globin gene and polyA sequence to stabilize transgene 
expression. We are in the process of excising human LTBP1-GFP from pHIV-ZsGreen described above in Figure 2 and inserting this into the rabbit beta globin sequence.

b) Generate lentiviral particles for inducible overexpression and knockdown of Ltbp1 (months 1-24)

Lentiviral sh1 described above in Task $2 \mathrm{~b}$ and Figure 6 has been designed to work in mouse as well as human cell lines.

c) Introduce lentiviral constructs into poorly MMTV-Neu/ErbB and highly metastatic MMTV-PyMT MECS and transplant into cleared fatpads.

We have purchased the the PyMT and MMTV-neu mice. These mice have been bred and a cohort maintained for tumor development as a source of primary tumor mammary epithelial cells that we can infect with lentiviral construct described in Figures 5 and 6 above and reintroduce into hosts to determine the effects of modulating LTBP1 on tumor progression.

$>$ What opportunities for training and professional development has the project provided.

1. Dr. Catina Crismale Gann has taken a course in "Translating Cancer Discovery into Clinical Practice" and one on one mentoring on mammary stem cells.

2. Dr. Gann has acquired skills in mammary epithelial cell preparation, FACS analysis and transplantation.

3. Dr. Gann has acquired skills in Lentiviral construction.

\section{How were the results disseminated to communities of interest}

1. Dr. Cowin has presented this work in two seminars at Rutgers Department of Animal Science and at UMDNJ/Rutgers Cancer Center.

2. Dr. Cowin presented this work to incoming graduate student candidates of the Pharmacology training program of the NYU Sackler Graduate Institute.

3. This work has been presented to the NYU Developmental Genetics and Stem Cell Work in Progress meeting.

4. We have assembled a committee to whom the postdoctoral fellow reports for guidance that includes three external scientists with relevant expertise who are also breast cancer survivors: Dr. Stephanie Diment, Nature publisher,New York, Dr. Cara Gottardi, Northwestern University and Dr. Juliet Daniels, McMaster University.

What do you plan to accomplish during the next reporting period to accomplish the goals and objectives

1. Determine conditions for epitope retrieval to permit LTBP1 detection in archival samples of breast cancer and collect fresh frozen samples from the biorepository.

2. Characterize cell lines lentivirally expressing LTBP1 and begin analysis of their migratory properties in vitro and in vivo

3. Perform pronuclear injection to generate LTB1 transgenic lines..

4. Generate a source and repository of tumorigenic mammary epithelial cells (MECS) from MMTV-PyMT and MMTV-neu mice for LTBP1 manipulation. 


\section{IMPACT}

$>$ What was the impact on the development of the principal discipline of the project.

Our results have highlighted the concept that the actions of the breast tumor suppressor and metastasis promoter TGFbeta are spatially and temporally restricted in a very dynamic spatio-temporal pattern during breast development and are not, as thought previously, ubiquitously available to all mammary cells. This means TGFbeta activity in terms of signaling within responding cells is very tightly controlled by LTBP1 expression. Our data also reveal that fibrillin and elastin are expressed at significant levels within breast stroma. There are no studies on LTBP1, fibrillin or elastin in breast so this has opened up a new field of study in stromal composition of the breast.

Our unpublished data reported herein indicat that LTBP1 expression has value as a prognostic indicator of patient outcome in HER2 and Basal type breast cancer.

\section{What was the impact on other disciplines}

The expression pattern of LTBP1 suggests it may play a critical role in regulating epithelial stem cell quiescence and survival that could be relevant in many epithelial tissues and cancers.

What was the impact on technology transfer Nothing to report

$>$ What was the impact on society beyond science and technology Nothing to report as yet but linking breast development factor to breast cancer risk opens the door to preventative strategies linked to reproductive history.

\section{CHANGES/PROBLEMS}

Delays in approach and reasons for delay Nothing to report

Actual anticipated problems or delays and actions or plans to resolve them Nothing to report

$>$ Changes that had a significant impact on expenditures - There was a delay in hiring a suitable postdoctoral fellow.

$>$ Significant changes in use or care of human subjects, animals, biohazards or select agents - Nothing to report

\section{PRODUCTS}

$>$ Publications, conference papers and presentations

- Journal Publications: 
Author: Chandramouli A, Simundza J, Pinderhughes A, Hiremath M, Droguett G, Frendewey D, Cowin P.

Title: Ltbp1L is focally induced in embryonic mammary mesenchyme, demarcates the ductal luminal lineage and is upregulated during involution.

Journal: Breast Cancer Res. doi: 10.1186/bcr3578.PMID: 24262428

Volume: $15(6)$

Year: 2013

Page numbers: R111 (1-18)

Status: Published

Acknowledgement of Federal Support: YES

- Books etc: Nothing to report

- Other publications, conference papers and presentations

1. Dr. Cowin has presented this work in two seminars at Rutgers Department of Animal Science and at UMDNJ/Rutgers Cancer Center.

Website(s) or other internet site (s): Nothing to report

$>$ Technologies or Techniques: Nothing to report

Inventions, patent applications and/or licenses: Nothing to report

Other products:

○ Research material: Generation of lentiviral LTBP1 expression and hairpin constructs

\section{PARTICIPANTS AND OTHER COLLABORATING ORGANIZATIONS}

Individuals working on the project:

\begin{tabular}{|l|l|}
\hline Name & Pamela Cowin \\
\hline Project Role & P.I. \\
\hline Research Identifier & \\
\hline Nearest person month worked & 12 \\
\hline Contribution to project & Directed research \\
\hline Funding Support & DOD BC123572 20\% \\
\hline
\end{tabular}

\begin{tabular}{|l|l|}
\hline Name & Catina Crismale Gann \\
\hline Project Role & Postdoctoral fellow \\
\hline Research Identifier & \\
\hline Nearest person month worked & 3 \\
\hline Contribution to project & Performed work on Aim 1 \\
\hline Funding Support & DOD BC123572 100\% \\
\hline
\end{tabular}




\section{Has there been a change in the active support of the PI or senior key personnel since the last reporting period}

P.I. Dr. Pamela Cowin - No change

Postdoctoral Fellow - Dr. Catina Crismale Gann - No change during this reporting period - going forward Dr. Gann has received support from NIH postdoctoral training grant fellowship program and will be replaced on this project by a new hire.

$>$ What other organizations were involved as partners?

Regeneron Inc.

Tarrytown, NY

G. Droguett and D. Frendewey performed qPCR analysis of LTBP1 expression for us using RNA samples from our laboratory for the published paper below.

\section{SPECIAL REPORTING REQUIREMENTS N/A}

\section{APPENDICES}

\section{Journal article:}

Chandramouli A, Simundza J, Pinderhughes A, Hiremath M, Droguett G, Frendewey D, Cowin P.

"Ltbp1L is focally induced in embryonic mammary mesenchyme, demarcates the ductal luminal lineage and is upregulated during involution".

Breast Cancer Res. 2013 Nov 21;15(6):R111. doi: 10.1186/bcr3578.

PMID: 24262428 PMCID: PMC3978911 


\section{Breast Cancer}

BA RESEARCH

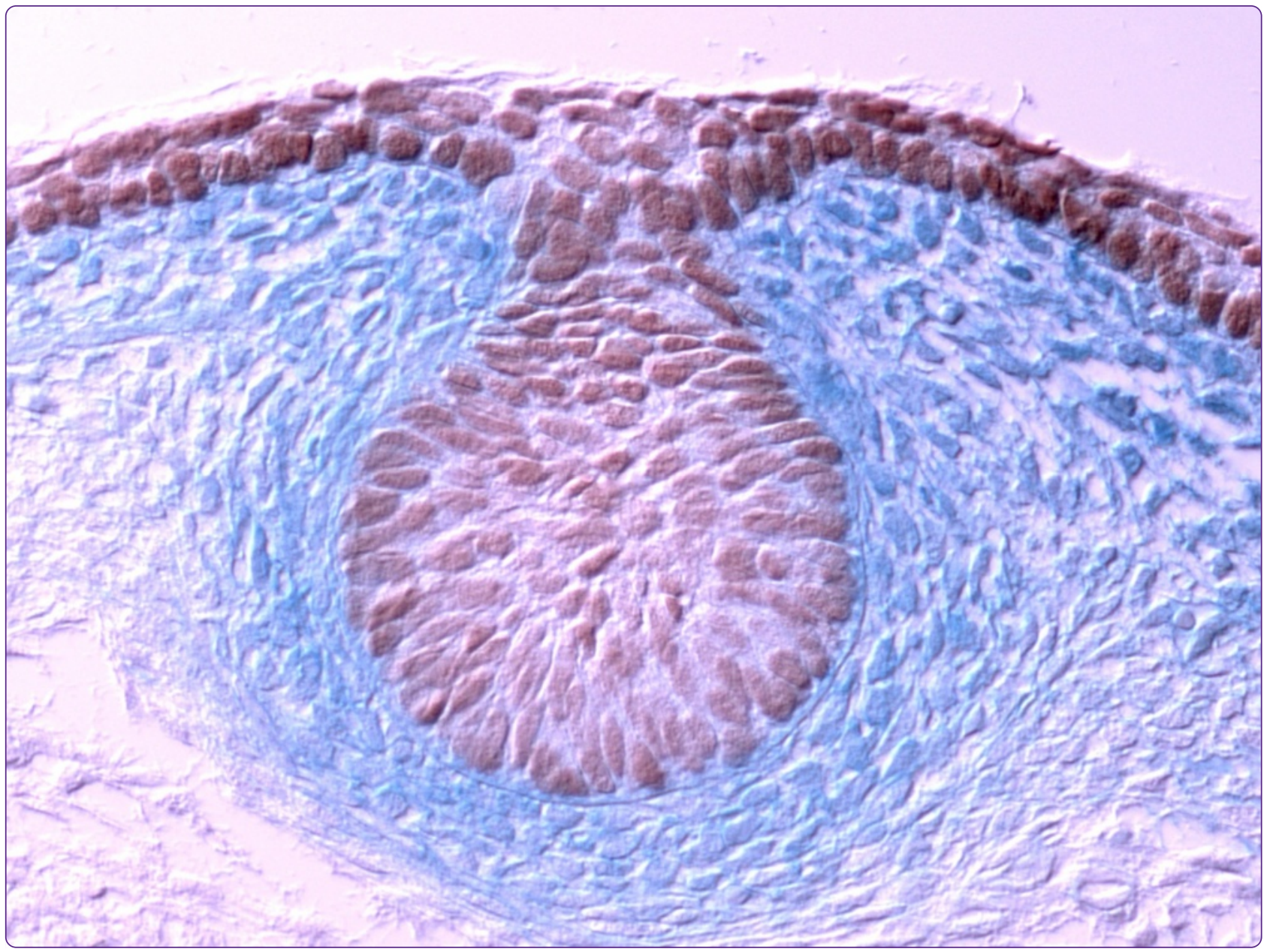

$L t b p 1 L$ is focally induced in embryonic mammary mesenchyme, demarcates the ductal luminal lineage and is upregulated during involution

Chandramouli et al. 


\title{
Ltbp $1 L$ is focally induced in embryonic mammary mesenchyme, demarcates the ductal luminal lineage and is upregulated during involution
}

Anupama Chandramouli ${ }^{1,2+}$, Julia Simundza ${ }^{1,2+}$, Alicia Pinderhughes ${ }^{1 \dagger}$, Minoti Hiremath $^{1}$, Gustavo Droguett ${ }^{3}$, David Frendewey ${ }^{3}$ and Pamela Cowin ${ }^{1,2^{*}}$

\begin{abstract}
Introduction: Latent TGF $\beta$ binding proteins (LTBPS) govern TGF $\beta$ presentation and activation and are important for elastogenesis. Although TGF $\beta$ is well-known as a tumor suppressor and metastasis promoter, and LTBP1 is elevated in two distinct breast cancer metastasis signatures, LTBPs have not been studied in the normal mammary gland.

Methods: To address this we have examined $L$ tbp 1 promoter activity throughout mammary development using an Ltbp1L-LacZ reporter as well as expression of both Ltbp1L and 1S mRNA and protein by qRT-PCR, immunofluorescence and flow cytometry.

Results: Our data show that $L t b p 1 L$ is transcribed coincident with lumen formation, providing a rare marker distinguishing ductal from alveolar luminal lineages. $L$ tbp $1 L$ and $L t b p 1 S$ are silent during lactation but robustly induced during involution, peaking at the stage when the remodeling process becomes irreversible. Ltbp $1 \mathrm{~L}$ is also induced within the embryonic mammary mesenchyme and maintained within nipple smooth muscle cells and myofibroblasts. Ltbp1 protein exclusively ensheaths ducts and side branches.

Conclusions: These data show $L t b p 1$ is transcriptionally regulated in a dynamic manner that is likely to impose significant spatial restriction on TGF $\beta$ bioavailability during mammary development. We hypothesize that Ltbp1 functions in a mechanosensory capacity to establish and maintain ductal luminal cell fate, support and detect ductal distension, trigger irreversible involution, and facilitate nipple sphincter function.
\end{abstract}

\section{Introduction}

Latent transforming growth factor $\beta$ (TGF $\beta$ ) binding proteins (LTBPs) are regulators of elastogenesis and TGF $\beta$ [1]. Their critical role in tissue development, homeostasis and resilience is demonstrated by the fact that LTBP lossof-function mutations underpin a growing list of human genetic syndromes [2-4]. Gain of LTBP gene expression also has pathological consequences: $L T B P 1$ is upregulated in two breast cancer metastasis signatures and is one of only six genes found in common to both $[5,6]$.

\footnotetext{
* Correspondence: cowinp01@nyumc.org

${ }^{\dagger}$ Equal contributors

'Department of Cell Biology, New York University School of Medicine, New York, NY, USA

${ }^{2}$ The Ronald O Perelman Department of Dermatology, New York University School of Medicine, 550 First Ave, New York, NY 10016, USA

Full list of author information is available at the end of the article
}

Ltbp genes encode a family of secreted proteins, Ltbp1-4, that show extensive sequence homology to fibrillins, which polymerize to form microfibrils and coat elastic fibers $[1,7]$. Ltbp proteins are initially deposited onto fibronectin and later transferred to microfibrils by interaction with fibrillins [8]. Their importance for the structural integrity and tensile function of the extracellular matrix $(E C M)$ is illustrated by the pathologies seen in Ltbp $4 S$-null mice resulting from defective elastic-fiber formation in the intestine, lung and pulmonary artery and in humans with Urban-Rifkin-Davis syndrome $[4,9,10]$.

In addition to their contribution to ECM structure, Ltbp1, Ltbp3 and to a lesser extent Ltbp4 govern the spatial patterning and activation of TGF $\beta$. TGF $\beta$ s are secreted in a latent form, encapsulated by their cleaved latency-associated propeptide (LAP), and deposited within the ECM for subsequent activation. Ltbps post-

\section{Biomed Central}

(c) 2013 Chandramouli et al.; licensee BioMed Central Ltd. This is an open access article distributed under the terms of the Creative Commons Attribution License (http://creativecommons.org/licenses/by/2.0), which permits unrestricted use, distribution, and reproduction in any medium, provided the original work is properly cited. 
translationally regulate TGF $\beta$ in three ways. First, they chaperone the association of TGF $\beta$ with LAP and through preferential binding affinities control which of three TGF $\beta$ isoforms emerge from the cell [11]. Second, Ltbps incorporate latent TGF $\beta$ within the ECM thereby determining where TGF $\beta$ is presented to its receptors [12]. Third, Ltbps provide a key link between the ECM and the cell surface that is essential for stretch activation of TGF $\beta$ [13-15]. Both integrins and Ltbp bind to LAP. Thus, when Ltbp1 is anchored in a stiff ECM and stress fibers exert tension on integrins, conformational changes occur in LAP that lead to release of the active TGF $\beta$ $[13,14,16]$. One major response to TGF $\beta$ signaling is synthesis of new matrix proteins [17]. Thus, Ltbps create a mechanosensory system that generates a highly localized feedback response to cell traction or tension within the microenvironment $[1,18]$.

Mouse mutants have illuminated the roles of Ltbps in tissue homeostasis and their involvement in human pathology. Ltbp1 hypomorphs show facial dysmorphia [19] and $L t b p 1 L$ loss leads to embryonic lethality due to heart malformation [20], Ltbp2 loss-of-function mutations cause glaucoma in humans and lens defects in mice [21], Ltbp3 loss-of-function mutation results in severe bone malformation [3,22,23] and Ltbp $4 S$-null mice show multiple organ defects $[4,9,10]$. In some mutants the prevailing pathology reflects compromised elastogenesis [10,24]. In others the phenotype can be ameliorated by concurrent deletion or pharmacological antagonism of TGF $\beta$, supporting the central role of Ltbps in TGF $\beta$ biology and pathology [10].

Three TGF $\beta$ isoforms are differentially expressed and exert multiple effects during mammary development [25]. Loss- and gain-of-function studies have shown that TGF $\beta$ signaling restrains pubertal ductal extension and side branching by stimulating Wnt5a expression [26-31]. TGF $\beta 1$ influences stem cell regenerative potency and cell-fate determination and has been proposed to suppress precocious alveologenesis in the adult gland prior to pregnancy [27,32-36]. Weaning massively induces TGF 33 expression, and this surge is essential for the demise of the differentiated glandular epithelium and remodeling events during mammary involution [37,38]. TGF $\beta 1$ has also been the object of intense investigation due to its pathological relevance for breast cancer $[39,40]$ where it acts as a tumor suppressor in premalignant lesions and at later stages promotes metastasis through induction of epithelial-to-mesenchymal transition (EMT).

Knowledge of Ltbp's temporal and spatial expression pattern is central to understanding TGF $\beta$ signaling both in the physiological setting of the normal mammary gland and in breast cancer. Yet to date there have been no studies on Ltbp within the normal mammary gland.
Here we show that $L t b p 1$ is induced in a highly specific temporal and spatial pattern throughout mammary development, supporting the concept that dynamic transcriptional regulation of $L t b p 1$ provides a mechanism to impose considerable restriction on TGF $\beta$ bioavailability. $L t b p 1 L$ is upregulated early during embryonic mammary mesenchyme specification and is sustained in smooth muscles of the nipple sphincter. Within the mammary gland, $L t b p 1 L$ is induced exclusively in the ductal luminal epithelium but is silent in alveoli and therefore provides a rare biomarker distinguishing ductal from alveolar luminal lineages. Ltbp1 protein is deposited around basal cells of all ducts and side branches, and lies in close proximity to elastic fibers that exclusively encase the permanent ductal system. Ltbp 1 is prominently upregulated during involution, with kinetics similar to that reported for TGF 33 , suggesting important functions in gland remodeling.

\section{Methods}

Mice

$L t b p 1 L^{l z /+}$ mice, were generated by Regeneron Pharmaceuticals, Inc., Tarrytown, NY. VelociGene methods [41] were used to recombineer a bacterial artificial chromosome (BAC) clone, such that a region extending from the 165th codon of murine $L t b p 1 L$ in exon 2 through the remainder of exon 2 and $7.8 \mathrm{~kb}$ into the downstream intron, was replaced by homologous recombination with an expression cassette comprising the transmembrane domain of ROR1 fused in-frame with the upstream coding sequence of $L t b p 1 L$, followed by a stop-transfer sequence, a modified $\beta$-galactosidase coding sequence (lac $Z$ ), a polyadenylation signal and an antibiotic selection cassette flanked by $\operatorname{lox} P$ sites [42] (see Figure 1). The modified BAC, was linearized, producing $5^{\prime}$ and $3^{\prime}$ homology arms of approximately $150 \mathrm{~kb}$ and $30 \mathrm{~kb}$ flanking the deletion, and electroporated into SvEv129/C57Bl6/F1-derived hybrid embryonic stem (ES) cells. Targeting of ES cells and the germline transmission were confirmed by a quantitative reverse transcriptase PCR (qRT-PCR) assay that scored for the loss of one of the native $L t b p 1 L$ alleles [41]. The $n e o^{R}$ cassette was removed by crossing with mice expressing Cre recombinase in the germ-cell lineage and the knockout was confirmed by northern and western analysis [20]. Ltbp1L $\mathrm{L}^{\mathrm{lz} /+}$ mice on a mixed C57Bl6/129 background were rederived into the Skirball animal facility and crossed onto an FVBN strain background by breeding through nine generations. All animal protocols were approved by the Institutional Animal Care and Use Committee (IACUC) of New York University School of Medicine.

Carmine staining of mammary whole mounts revealed no differences between $L t b p 1 L^{l z /+}$ mice and wild-type littermates in ductal elongation, branching, alveolar development or involution. Pups from both genotypes faired 


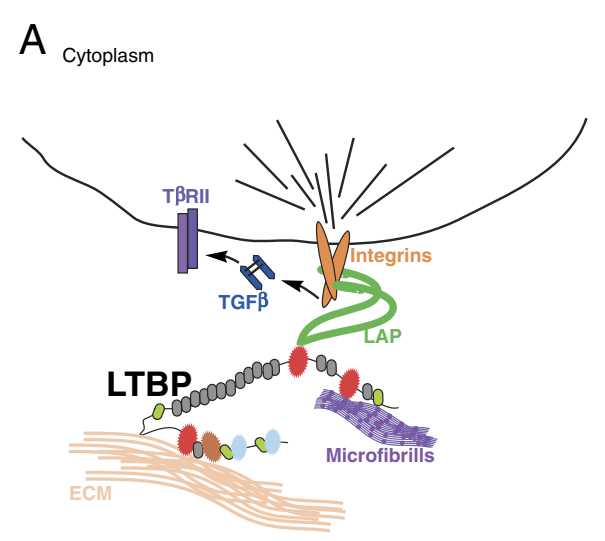

B

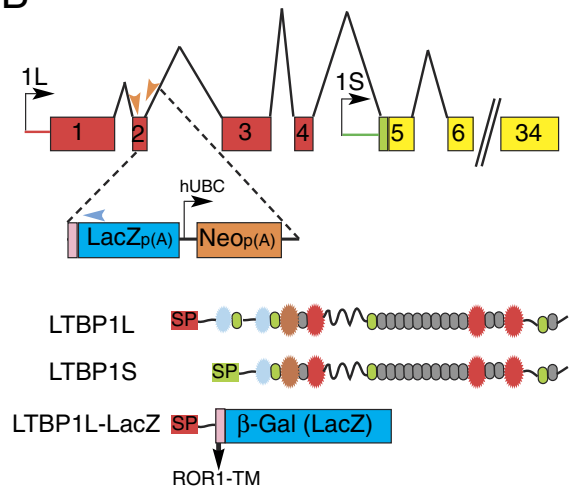

Figure 1 Latent TGF $\beta$ binding protein (Ltbp) function and reporter construct. (A) Ltbp1 sequesters TGF $\beta$ ligand encased by its latency associated propeptide (LAP) within the extracellular matrix (ECM). Integrins also interact with LAP. Cytoskeletal tension on integrins stretches LAP and releases TGF $\beta$ locally to activate the TGF $\beta$ receptor II (TRRII). (B) Two Ltbp1 isoforms (1L and $1 \mathrm{~S}$ ) are transcribed from distinct promoters (black arrows, top). The first four exons (red boxes) encode sequence unique to Ltbp1L. The promoter, transcription start site and unique signal peptide sequence for Ltbp1S (green line and box) lie within the 4th intron of Ltbp 1L. Black lines indicate introns. The targeted deletion of $L t b p 1 L$ replaces codon 165 in exon 2 through $7.8 \mathrm{~kb}$ of intron 2 with a cassette comprising the ROR1 transmembrane domain (pink box), a modified lacZ gene and polyadenylation signal (blue box) as well as a floxed neomycin gene (orange box) driven by the human ubiquitin binding complex promoter (hUBC) that was removed by cre recombination in embryonic stem cells. Orange and blue arrowheads indicate primers used for genotyping. 1L and $1 \mathrm{~S}$ isoforms contain a signal peptide (SP), 4-Cys (blue), 8-Cys (red) and epidermal growth factor (EGF)-like repeats (gray and green), and unique 8-cys/EGF hybrid domains (brown). The Ltbp1L-LacZ reporter comprises the signal peptide and the first 165 amino acids of Ltbp1L protein followed by the ROR1 transmembrane domain fused in-frame with $\beta$-galactosidase and lacks all functional LTBP1 domains.

equally well in terms of weight gain (data not shown). We concluded that $L t b p 1 L^{l z /+}$ mice show no evidence of haploinsufficiency and justified their use to study the regulated expression of $L t b p 1 L$ during mammary development. Staging of pregnancy and embryos were performed by daily checking of vaginal plugs, with noon of the day of the plug considered day 0.5. Embryonic stages were confirmed by determining the degree of limb development as indicated in Theiler's classification of mouse development (The Atlas of Mouse Development, MH Kaufman).

\section{Genotyping}

Mice and embryos were screened by 5 -bromo-4-chloro3 -indolyl- $\beta$-D-galactoside (X-Gal) staining of tails and confirmed by PCR analysis. Genomic DNA was prepared from $0.5 \mathrm{~cm}$ of tail by digesting overnight in $0.5 \mathrm{ml}$ digestion buffer (50 mM Tris- $\mathrm{HCl} \mathrm{pH} \mathrm{7.4,} 100 \mathrm{mM}$ ethylenediaminetetraacetic acid (EDTA), $100 \mathrm{mM} \mathrm{NaCl}, 0.5 \%$ SDS, $200 \mu \mathrm{g} / \mathrm{ml}$ proteinase K). Then $150 \mu \mathrm{l}$ of $5 \mathrm{M} \mathrm{NaCl}$ was added and the digest was agitated for 15 minutes on a rotator: $500 \mu \mathrm{l}$ of supernatant was collected after centrifugation at 14,000 G for 15 minutes, and subjected to two rounds of ethanol precipitation. The final pellet was resuspended in $200 \mu \mathrm{l}$ TE $(10 \mathrm{mM}$ Tris- $\mathrm{HCl} \mathrm{pH} \mathrm{7.4,}$ $1 \mathrm{mM}$ EDTA) and $1 \mu \mathrm{l}$ was added to a $20-\mu \mathrm{l}$ PCR. Thirty cycles of PCR $\left(94^{\circ} \mathrm{C}, 58^{\circ} \mathrm{C}\right.$ and $72^{\circ} \mathrm{C}$ for 1 minute each) were carried out. The wild-type $L t b p 1 L$ allele was detected by amplification of a 430-bp band using forward $5^{\prime}-\mathrm{CT}$ TAGTTCCTCCATCCTTCC-3' and reverse 5' ${ }^{\prime}$-CAGA
CTTCACCTTCCCAGGG-3' primers. The Ltbp1L $\mathrm{L}^{\mathrm{lz} /+}$ knock-in allele was detected in a separate reaction using the forward primer listed above and a reverse primer 5GTCTGTCCTAGCTTCCTCACTG-3' (see Figure 1B arrowheads) to amplify a 440-bp product. The gender of embryos was determined by amplification of the Sry gene on the Y chromosome (forward primer: 5'-GAGAGCATG GAGGGCCAT-3' and reverse primer: 5'-CCACTCCTC TGTGACACT-3'). Amplification products were resolved by electrophoresis on $2 \%$ agarose gels run for $30 \mathrm{mi}-$ nutes in TAE electrophoresis buffer $(40 \mathrm{mM}$ Tris-acetate, 1 mM EDTA).

\section{X-Gal staining of embryos and mammary gland whole mounts}

Embryonic day (E) 10.0 to E15.5 embryos were dissected and fixed in 4\% paraformaldehyde (PFA) (Sigma Aldrich, St Louis, MO, USA) prepared in PBS for 20 to $50 \mathrm{mi}$ nutes depending on the stage. Skin with attached mammary fat pads was removed from E16.5 to E18.5 embryos and stretched carefully on cardboard, and mammary glands from adult mice were dissected and flattened onto glass slides then fixed in 4\% PFA for 30 minutes. Following fixation, samples were washed $4 \times$ 15 minutes with rinse buffer $(2 \mathrm{mM} \mathrm{MgCl} 2,0.1 \%$ sodium deoxycholate, $0.2 \%$ NP40 prepared in PBS) and stained in X-Gal staining solution (5 $\mathrm{mM}$ potassium ferricyanide, $5 \mathrm{mM}$ potassium ferrocyanide, $1 \mathrm{mg} / \mathrm{ml} 5$-bromo-4chloro-3-indolyl-b-D-galactopyranoside (X-Gal, Denville Scientific, South Plainfield, NJ, USA) prepared in rinse 
buffer) at room temperature for 2 to $3 \mathrm{~h}$. After staining, samples were rinsed twice in PBS and post-fixed in $4 \%$ PFA overnight at $4{ }^{\circ} \mathrm{C}$, dehydrated through an ethanol gradient $(2 \times 10$ minutes in $70 \%, 95 \%$, and $100 \%$ ethanol), then placed in Carnoys's fixative (60\% ethanol, $30 \%$ chloroform, $10 \%$ glacial acetic acid) followed by Citrisolv reagent (Fisher Scientific, Pittsburgh, PA, USA) to clear the fat.

\section{Whole-mount carmine staining}

$\mathrm{X}$-Gal stained mammary glands were rehydrated in a reverse-graded series of ethanol washed in water and then stained for $1 \mathrm{~h}$ in carmine solution diluted 1:5 in water. Carmine was prepared by boiling $1 \mathrm{~g}$ carmine alum and $2.5 \mathrm{~g}$ aluminium potassium sulphate in $500 \mathrm{ml}$ of water for 20 minutes followed by filtration. The glands were dehydrated in a graded ethanol series, cleared in Carnoy's solution, placed in Citrisolv for 30 minutes, and mounted in Cytoseal (VWR, Radnor, PA, USA). Glands were then viewed using a Zeiss Axiovert (Oberkochen, FRG) brightfield microscope.

\section{Histology and immunodetection}

E10.5-stage embryos were embedded in 10\% gelatin, sectioned at $70 \mu \mathrm{m}$ with a vibratome, and mounted with Fluoromount G (Southern Biotech, Birmingham, AL, USA). Older embryos and mammary glands were processed for X-Gal staining and fixation as described above. Isopropanol was substituted for xylene to prevent diffusion of the X-Gal stain during processing and tissues were embedded in paraffin and sectioned. Sections $(4 \mu \mathrm{m})$ were placed on Superfrost Plus slides, baked $1 \mathrm{~h}$ at $60^{\circ} \mathrm{C}$ and deparaffinized for 5 minutes in Citrisolv for X-Gal-stained tissues. Tissues were then rehydrated through a reverse gradient of ethanol solutions. For histology, sections were stained with $0.1 \%$ solution of Nuclear Fast Red (NFR) (Polyscientific, Bayshore, NY, USA) for 1 minute. Tissues were then dehydrated and dipped in xylene (or Citrisolv in the case of X-Gal-stained tissues) before being mounted in Cytoseal (VWR). For immunohistochemistry (IHC), citric acid antigen retrieval was performed by submerging the slide containing deparaffinized $4-\mu \mathrm{m}$ sections in $10 \mathrm{mM}$ sodium citrate solution ( $\mathrm{pH}$ 6.0) and boiling in a microwave at $90 \%$ power for 30 minutes, followed by quenching of endogenous peroxidase using 3\% hydrogen peroxide. Primary mouse antibodies against smooth-muscle actin (SMA) 1 (1:500, DAKO, Carpinteria, CA, USA), estrogen receptor (1:500, DAKO), p63 (1:1,000 LabVision, Kalamazoo, MI, USA), and rabbit antibodies against Cytokeratin 14 (1:8,000, Covance, Princeton, NJ, USA), Lef-1 (1:100 Cell Signaling, Danvers, MA, USA), androgen receptor (1:500, Santa Cruz Biotechnologies, Santa Cruz, CA, USA) and guinea pig antibodies against Vimentin $\left(1: 1,000\right.$, Progen) were added overnight at $4^{\circ} \mathrm{C}$.
For IHC, biotin-labeled secondary antibodies $(1: 1,000)$ and streptavidin-horseradish peroxidase (HRP) (1:200, Vector Laboratories, Burlingame, CA, USA) were added for $30 \mathrm{mi}-$ nutes each, and colorimetrically detected with diaminobenzidine (Vector Labs). Frozen $5-\mu \mathrm{m}$ sections were stained with rabbit antibodies against LTBP (Ab39 [43], 1:200, a gift from Dr Carl-Henrik Heldin, Uppsala University, Sweden, and rL1C [44], 1:100, a gift from Dr Lynn Sakai, Portland Shriners Research Center, Portland, OR, USA), tropoelastin (1:500, Elastin Products Company, Inc., Owensville, MO, USA), and mouse anti-SMA, described above, were detected by Cy3-labeled donkey anti-rabbit (Fisher Scientific) and Alexafluor-488-labeled donkey anti-mouse secondary antibodies (Life Technologies Inc, Carlsbad, CA, USA). Bioreagent (4',6-diamidino-2-phenylindole dihydrochloride (DAPI) from Sigma Aldrich) was used for immunofluorescent localization of nuclei in confocal images. Elastic fibers were also detected by staining with Wiegert's resorcin-fuchsin for 1 minute [45].

\section{Mammary epithelial cell preparation and flow cytometry}

The third, fourth and fifth mammary glands from 8- to 16-week-old virgins were dissected, inguinal lymph nodes were discarded, and the mammary glands were minced between two scalpels into a fine paste. The tissue was dissociated for $6 \mathrm{~h}$ at $37^{\circ} \mathrm{C}$ in collagenase/hyaluronidase solution (catalog number 07912, Stem Cell Technologies Inc., Vancouver, BC, Canada), and further dissociated with $0.25 \%$ Trypsin-EDTA and $10 \mathrm{mg} / \mathrm{ml}$ dispase (catalog number 07913, Stem Cell Technologies) with $1 \mathrm{mg} / \mathrm{ml}$ DNase, before filtering through a $40-\mu \mathrm{m}$ mesh. Endothelial and hematopoietic lineages were depleted using antibodies to TER119, CD45, CD140a, and CD31 (1:100, Becton Dickenson (BD), Franklin Lakes, NJ), with three separations on an EasySep magnet. Primary antibodies CD49f-PerCP-Cy5.5 (1:200, BD), CD24-PE (1:400, BD), CD29-Pacific Blue (1:200, Biolegend, San Diego, CA, USA), CD61-APC (1:200, CalTag MedSystems, Buckingham, UK), stem cell antigen 1 (Sca1)-phycoerythrin (PE) (1:400, BD) were added for 30 minutes at $4^{\circ} \mathrm{C}$. Fluorescein Di- $\beta$-D-Galactopyranoside (FDG-gal) loading was performed after primary antibody staining, according to the manufacturer's instructions (FluoReporter Kit, Life Technologies, Green Island, NY, USA). Flow cytometry was performed on a BD LSRII or BD FacsCalibur, and analyzed using FlowJo v8.7.

\section{RNA isolation and qRT-PCR analysis}

The fourth and fifth pair of mammary glands were harvested from wild-type mice at different stages of postnatal mammary development, dissected and snap-frozen in liquid nitrogen. A block of tissue approximately $0.5 \times 0.5 \times$ $0.5 \mathrm{~cm}$ was homogenized for 5 minutes in $1 \mathrm{ml}$ of TRIReagent (Life Technologies) using a hand-held tissue 
homogenizer (Kinematica, Lucerne, Switzerland), then mixed with $200 \mu$ l of chloroform and centrifuged at $14,000 \mathrm{G}$ for 15 minutes to eliminate protein debris. The upper aqueous phase was mixed with an equal volume of 70\% ethanol and passed through a Qiagen RNeasy mini spin column by a brief 15 sec centrifugation at 8,000 $\mathrm{G}$ at room temperature. Total RNA bound to the column filters was washed in $350 \mu \mathrm{l}$ of ethanol-containing buffer (RW1 buffer; Qiagen, Valencia, CA, USA) to remove contaminants and incubated in $10 \mu \mathrm{l}$ of RNase-free DNase I enzyme (273 Kunitz units; Qiagen) for 15 minutes at room temperature to ensure digestion of any residual genomic DNA fragments. The columns were washed according to the manufacturer's instructions in ethanol-containing buffers (RW1 and RPE buffers; Qiagen). Total RNA was eluted in $50 \mu \mathrm{l}$ of RNase-free water, and its concentration was analyzed by Nanodrop measurement. Reverse transcription was performed using $2 \mu \mathrm{l}$ of RNA (10 $\mathrm{ng} / \mu \mathrm{l})$ from tissue using the QuantiTect Probe RT-PCR Kit (Qiagen; catalog number 204443). Real-time analysis was performed using the Taqman Gene Expression Assay (Applied Biosystems by Life Technologies; catalog number 4331182) for mouse Ltbp1 (Mm00498255_m1), Ltbp1L (Mm01226402_m1 spanning exons 1 and 2), and Ltbp1S (custom assay with forward primer: $5^{\prime}$-TTCCAAGGCAA GTTCATGGATA-3', within intron 4; reverse primer: 5' AGGAGTAGAGGCAGACAGAGAAAGA-3', within the fifth exon of $L t b p 1$ genomic sequence and MGB probe: 5' -6FAM-TAAGCTGATGTGTTTGTTG-3'-MGBNFQ) and mouse $\beta 2$-microglobulin (Mm00437762_m1). Realtime analysis was performed in the Applied Biosystems ViiA $^{\mathrm{Tm}}$ 7. Total Ltbp1, Ltbp1L and 1S mRNA levels were normalized to those of mouse $\beta 2$-microglobulin and plotted as levels relative to tissue from 12-week-old virgins.

\section{Results}

Ltbp1L-LacZ expression underlies a route for axillary cell migration and is an early marker of the mammary mesenchyme

We utilized an Ltbp1 $\mathrm{L}^{\mathrm{lz} /+}$ reporter mouse (Figure 1) in an attempt to understand potential physiological roles of LTBP1L [20]. Mammary development begins in mice at E10.5 with the formation of ectodermal ridges between the limbs, termed mammary lines that fragment to form placodes 3 and 4 [46]. Although Ltbp1L-LacZ expression was found between the limbs at this stage in $L t b p 1 L^{l z /+}$ embryos (Figure 2A black arrow), in sections it localized principally to internal viscera (Figure 2B black arrow). Robust Ltbp1L-LacZ expression first appeared at E11.5 to E12.0 in a subaxillary mesenchymal streak (Figure 2C and $\mathrm{D}$, white arrow) abutting mammary placodes 1 and 2 (Figure 2C, red arrows). Intriguingly, ectodermal cells have been shown to migrate along a similar path to form pectoral and thoracic placodes 1 to 3 [47]. Later Ltbp1L-

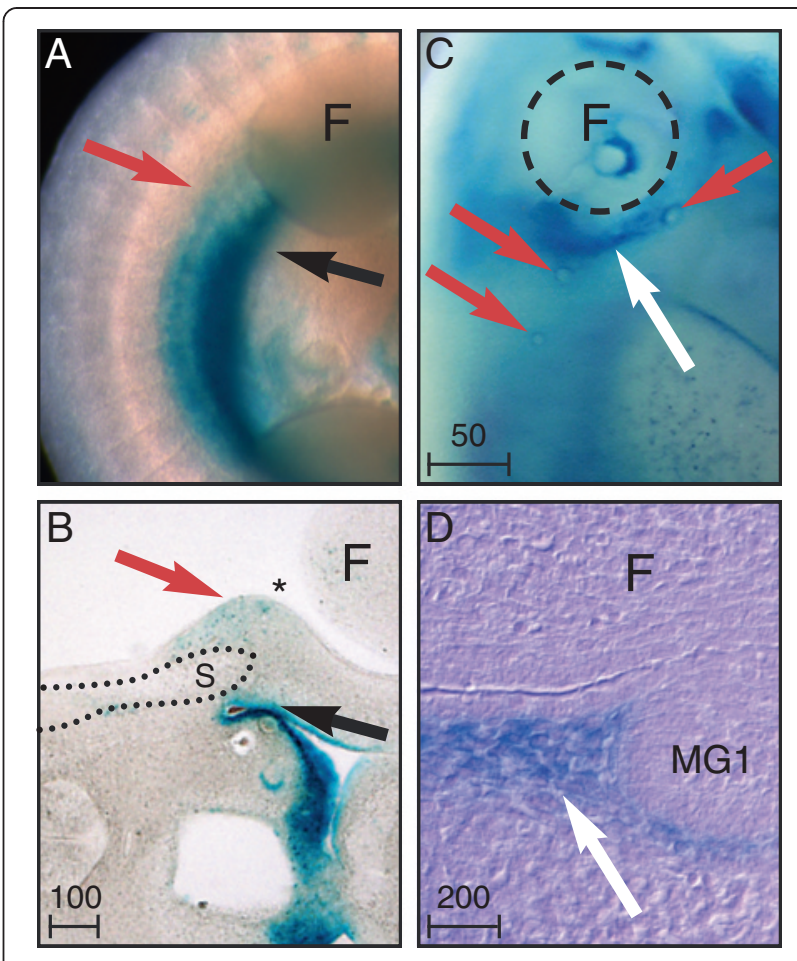

Figure 2 Latent TGF $\beta$ binding protein (Ltbp)1L-LacZ appears early in embryonic mammary development. The 5-bromo-4chloro-3-indolyl- $\beta$-D-galactoside (X-Gal)-stained embryonic day (E) 10.5 embryo (A) and vibratome section (B) show a broad stripe of Ltbp1L-LacZ (blue stain) that localizes to viscera (black arrow). Faint staining (red arrow) is seen at the dorsal border of the mammary line (asterisk) overlying the somitic tips (S). (C) X-Gal-stained E12.0 to E12.5 embryos show reporter expression in a streak along the forelimb axilla (white arrow) and surrounding placodes 1 to 3 (red arrows). (D) Nuclear fast red-counterstained section of the same region shows a gradient of Ltbp1L-LacZ in the mesenchyme (white arrow) oriented towards mammary gland 1 (MG1). F = forelimb. Scale bars represent distance in microns.

LacZ became intensely expressed around all five buds (Figure 3A-C) and colocalized with well-characterized mammary mesenchyme markers, such as androgen receptor (AR), estrogen receptor (ER), tenascin $C$ and lymphoid enhancer-binding factor 1 (Lef1) (Figure 3DG) [46]. Thus, during early embryonic mammary development $L t b p 1 L$ expression underlies a migratory route for epithelial cells and is one of the earliest markers of the inductive mammary mesenchyme.

\section{Mesenchymal Ltbp $1 L$ activity accompanies nipple induction and persists in smooth-muscle cells and myofibroblasts in the adult}

In males, stimulation of androgen receptors at E14.5 induces mammary mesenchymal constriction and atrophy leading to bud loss and failure of nipple formation [48]. In contrast, in females, mammary mesenchyme signaling 

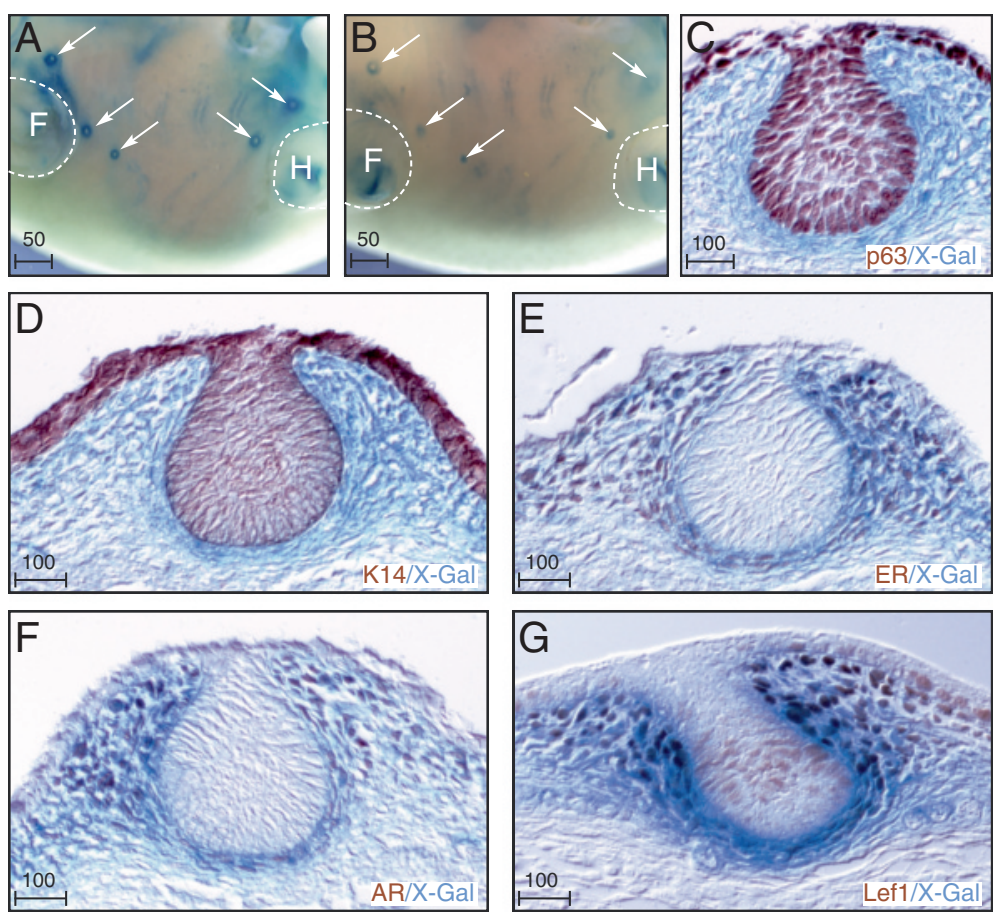

Figure 3 Latent TGF $\beta$ binding protein (Ltbp) 1 L-LacZ is an early marker of mammary mesenchyme. (A) The 5-bromo-4-chloro-3-indolyl- $\beta$ D-galactoside (X-Gal)-stained whole mount of embryonic day 14.5 female embryos. Ltbp1L-LacZ is expressed in a halo surrounding all mammary buds (white arrows). Expression is present but at lower levels in male embryos of the same stage (B, white arrows), coincident with the onset of sexual dimorphism. Localization of Ltbp1L-LacZ expression (blue stain) with immunohistochemical detection (brown stain) of epithelial markers p63 (C) and K14 (D), as well as mammary mesenchymal markers estrogen receptor (E), androgen receptor (F), and lymphoid enhancer-binding factor 1 (Lef1) (G). $\mathrm{H}$ = hindlimb, $\mathrm{F}=$ forelimb. Scale bars represent distance in microns.

induces ductal morphogenesis, differentiation of nipple epithelium and suppression of hair follicles within the areola [49]. Reflecting this sexual dimorphism, Ltbp1L-LacZ expression was diminished in E14.5 males (Figure 3B) and lost by E15.5 but was maintained in females (Figure 3A), and robustly expressed during nipple induction at E16.5 (Figure 4A, B). Once the nipple shield had formed, reporter expression became restricted to muscle cells of the areola (Figure 4C, D).

Nipples undergo significant postnatal connective tissue remodeling. In virgin and early pregnant mice, the nipple, delimited by germinative epidermal ingrowths, encloses predominantly collagenous connective tissue. During late pregnancy, nipple stromal cells proliferate and synthesize elastin, leading to elastic fiber hypertrophy [50]. Ltbp1LLacZ was strongly expressed in smooth muscle of the nipple sphincter, located at the base of the areola (Figure 5A-C), which were surrounded by elastic fibers (Figure 5D). Ltbp $1 L$ was silent within the nipple stroma at most developmental stages (Figure 5A, G, H). However, robust Ltbp1L reporter expression appeared briefly during mid-pregnancy P13.5 within vimentin-positive stromal cells (Figure 5E, F) at the base of the lactiferous duct and directly adjacent to the clefting germinative epithelium. Thus the temporal-spatial expression of $L t b p 1 L$ appears coincident with the formation of the nipple sphincter and during elastin synthesis by stromal myofibroblasts.

\section{Ltbp $1 L$ promoter activity coincides with ductal lumena formation within the embryonic mammary tree}

At E16 mammary mesenchymal signaling induces proliferation of a solid cord of cells to form the mammary sprout [46,49]. Ltbp1L remained silent within the epithelium at this stage (Figure 4B) but became robustly expressed at around E17.5, in luminal cells coincident with the appearance of microlumen (Figure 6B, D). Intriguingly, reporter expression was absent from the multilayered ductal tips (arrowheads, Figure 6E) and from portions of the lactiferous duct within the nipple that comprise stratified epithelium (Figure 6D). Thus, $L t b p 1 L$ is induced only when the lactiferous duct enters the fat pad and differentiates into a bi-layered tube comprising a simple epithelial luminal lining surrounded by molecularly distinct basal cells.

\section{Ltbp1 mRNA is dynamically modulated during postnatal development}

Mammary development continues postnatally during puberty and is completed only after a first pregnancy. To determine if $L t b p 1$ was expressed during the postnatal period we isolated total RNA from mammary glands 

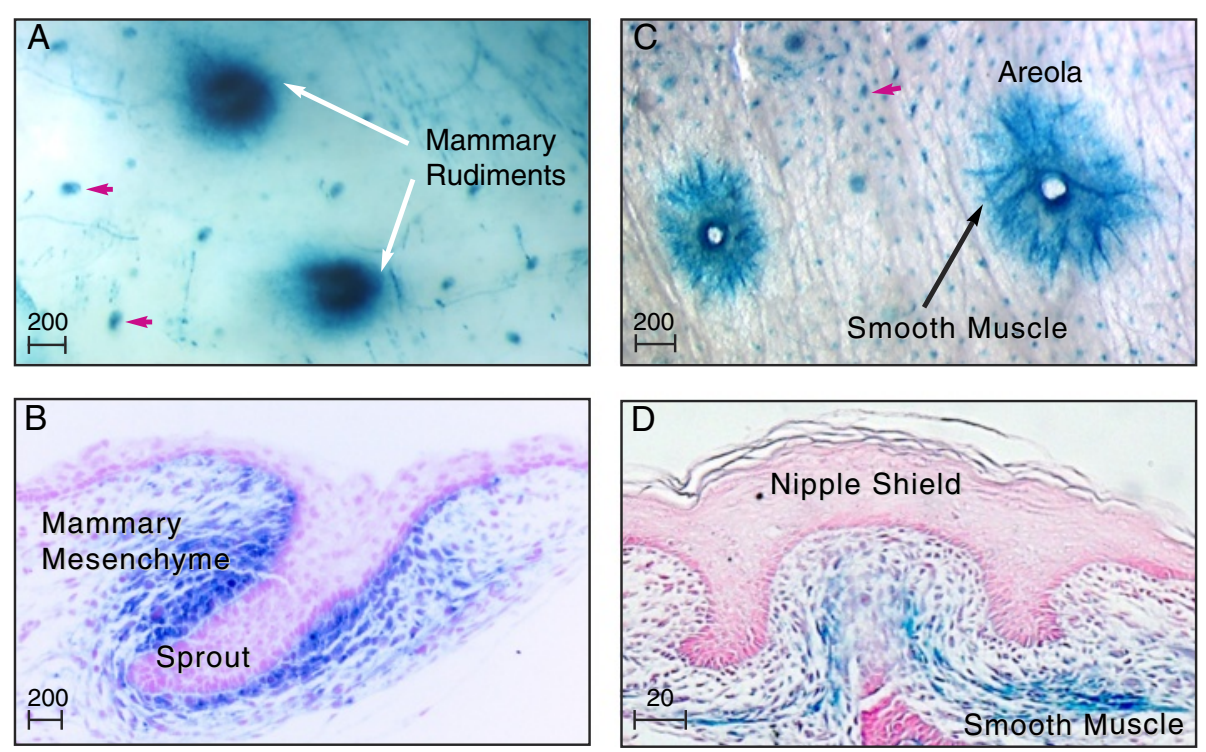

Figure 4 Mesenchymal Ltbp $1 L$ activity is upregulated coincident with embryonic nipple formation. (A) The 5-bromo-4-chloro-3-indolyl- $\beta$ D-galactoside (X-Gal)-stained skin whole mount (embryonic day16.5) shows robust Ltbp1L-LacZ expression (blue stain) in the mammary rudiments (white arrows) and developing hair follicles (red arrowheads). (B) Nuclear fast red (NFR)-counterstained section of the E16.5 mammary sprout shows strong focal Ltbp1L-LacZ expression in mammary mesenchyme at the onset of nipple induction. (C, D) Postnatal day 1 X-Gal-stained skin whole mount (C) and NFR-stained section (D) show Ltbp1L-LacZ expression in smooth-muscle cells at the base of the nipple shield extending radially into the developing areola. Scale bars represent microns.

of virgin, pregnant and lactating mice as well as from those undergoing post-parous remodeling (involution), and performed qRT-PCR. Total Ltbp1 mRNA was expressed at modest levels in virgin mice, decreased during pregnancy, lost during lactation and robustly upregulated during early involution, peaking at day 3 and returning to that found in virgins after 5 to 7 days (Figure 7A). Ltbp1S and $1 \mathrm{~L}$ showed a similar trend, however Ltbp1L rose in a more pronounced fashion at day 3 (Figure 7B).

\section{Ltbp $1 L$ is induced in ductal luminal cells and distinguishes them from alveolar lineages}

To determine more precisely where the $L t b p 1 L$ promoter is activated during postnatal mammary development, we examined Ltbp1L-LacZ expression in whole mounts and histological sections. In pubertal mice a balance of proliferation and apoptosis within outer cap and inner multilayered body cells of the bulbous terminal end buds (TEBs) generates the permanent ductal tree and creates a lumen in the subtending ductal system. X-Gal-stained whole mounts revealed Ltbp1L-LacZ expression lining the lumen of the TEB (Figure 7C). Reporter expression was notably absent from the vast majority of body cells, which are considered to be actively proliferating luminal precursors (Figure 7D).

Ltbp1L-LacZ was expressed prominently in luminal cells of the permanent ductal system (Figure 8A, B). To further characterize $L t b p 1 L$ activity within the luminal lineage we utilized a fluorescent $\beta$-Galactosidase substrate, FDG-Gal to detect Ltbp1L-positive cells by flow cytometry. Mammary stromal, basal, and luminal subpopulations can be separated by their differential expression of CD24, CD49f and CD29 (Figure 8C top panel) [51]: $65 \%$ of $\mathrm{CD} 24^{\text {high }} \mathrm{CD} 49 \mathrm{f}^{\text {low }}$ and $\mathrm{CD} 29^{\text {low }}$ luminal cells (Figure $8 \mathrm{C}$ middle panel and $8 \mathrm{D}$ respectively) were $\mathrm{FDG}^{+}$and therefore expressed Ltbp1L-LacZ. Interestingly, $35 \%$ of the luminal cell population was negative (Figure $8 \mathrm{C}$ bottom panel), consistent with our observation of a punctate $\mathrm{X}$-Gal staining pattern in some whole mounts (Figure 8A). Luminal cells can be further defined into mature and progenitor populations by their expression of CD61, a marker of integrin $\beta 3$ that is highly expressed in luminal progenitors and Sca1 [51]. The majority of $\mathrm{FDG}^{+}$cells were $\mathrm{Scal}^{+}$(Figure $8 \mathrm{E}$ ) and CD61- (Figure 8F), but a small percentage was CD61 ${ }^{+}$. Collectively these data indicate that $L t b p 1 L$ is induced in a subset of luminal progenitors and mature luminal cells of the permanent ductal system.

Pregnancy initially induces extensive arborization of the mammary ductal tree. Alveolar clusters form on the tip of each side-branch during mid-pregnancy and undergo secretory differentiation during late pregnancy in preparation for lactation. Mammary whole mounts taken during early, mid and late pregnancy showed Ltbp1L-LacZ expression throughout the permanent ductal system and within the newly developing transient side branches (Figure 9A-D). In striking contrast, Ltbp $1 L$ 

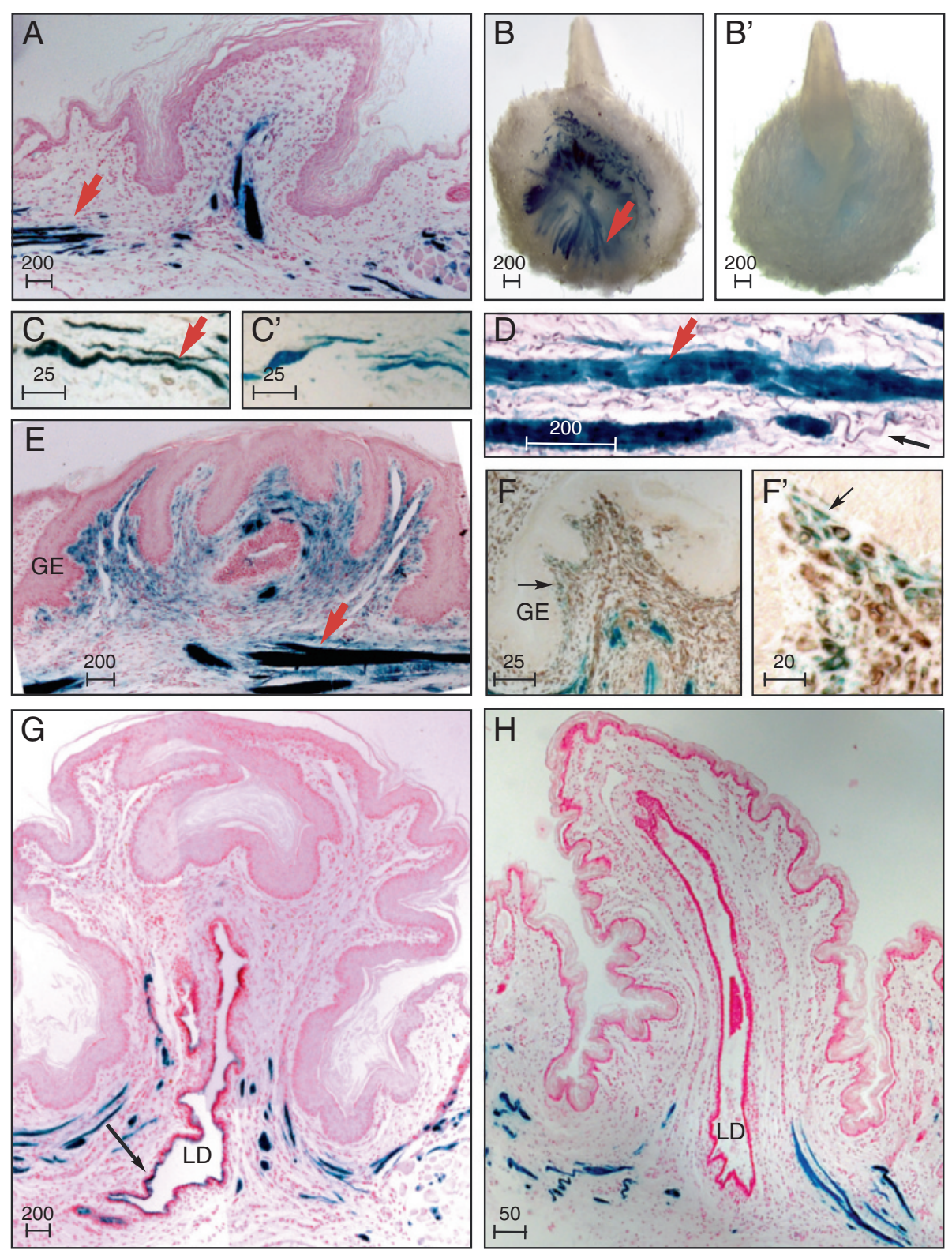

Figure 5 Sustained latent TGF $\beta$ binding protein (Ltbp)1L-LacZ expression in the specialized stroma of the adult nipple. (A-E) Robust Ltbp1L-LacZ expression was detected throughout postnatal development by 5-bromo-4-chloro-3-indolyl- $\beta$-D-galactoside (X-Gal) staining (blue stain) in bands of smooth-muscle cells (red arrows) at the base of the nipple underlying the areola in the region of the nipple sphincter

(A) Histological section through a nipple of a virgin mouse, counterstained with nuclear fast red (NFR). (B, B') Nipples from a pregnant (P14.5) mouse are shown from below (B) and above (B'). (C) Immunohistochemical detection of SMA 1 (brown stain) colocalizes with Ltbp1L-LacZ in areola smooth muscle, P13.5. Secondary antibody control (C'). (D) Resorcin-fuchsin stain detects elastin fibrils (black arrow to deep purple stain) encompassing Ltbp1L-LacZ-expressing smooth muscle. (E) NFR-stained section shows Ltbp1L-LacZ upregulation in nipple stromal cells during pregnancy, P13.5. (F, F') Colocalization of Ltbp1L-LacZ expression (black arrow to blue stain) with immunohistochemical detection of vimentin (brown stain) in stromal cells underlying the nipple germinative epithelium (GE) just prior to clefting, during pregnancy (P15.5). NFR-counterstained nipple sections from mice during $(\mathbf{G})$ pregnancy P16.5 and $\mathbf{( H )}$ involution. Note the absence of X-Gal staining in the region of the lactiferous duct (LD) within the nipple in $\mathbf{G}$ and $\mathbf{H}$ and acquisition of reporter expression as the LD enters the fat pad th the base of the nipple (see black arrow in $\mathbf{G}$ ). Scale bars represent distance in microns.

remained silent within developing and differentiating alveoli throughout pregnancy (Figure 9C, D). Histological sections through p16.5 alveolar clusters confirmed that Ltbp1L-LacZ expression was restricted to ducts and side branches (Figure 9E, F) and absent from alveolar milk-producing cells that contained large lipid droplets (Figure 9F). Thus $L t b p 1 L$ is a rare and highly specific marker distinguishing ductal from alveolar luminal lineages. 

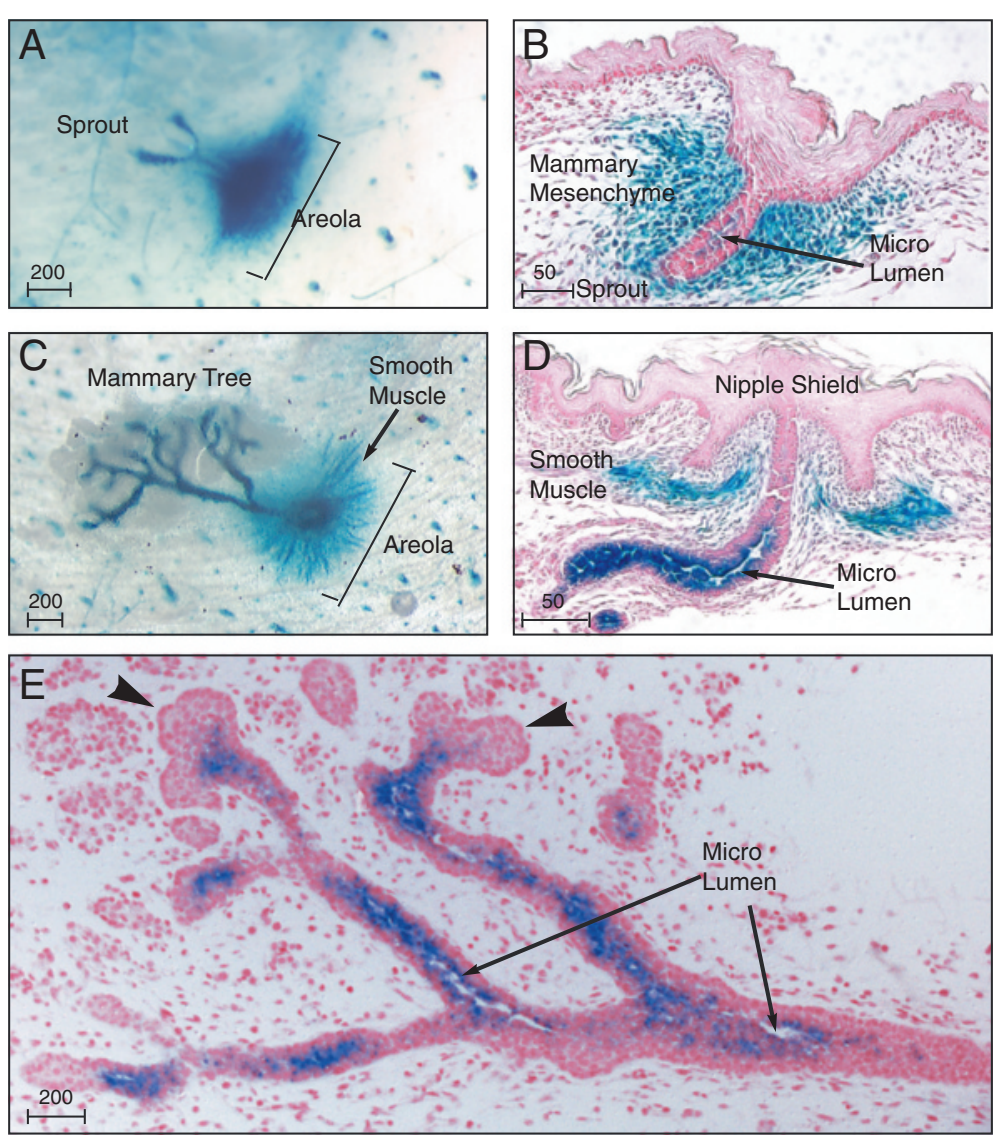

Figure 6 Latent TGF $\beta$ binding protein (Ltbp)1L-LacZ appears at the onset of lumen formation. (A) The 5-bromo-4-chloro-3-indolyl- $\beta$-Dgalactoside (X-Gal)-stained whole mounts (A, C) and sections counterstained by nuclear fast red (B, D, E) at embryonic day (E) 17.5 (A, B), postnatal day 1 P1 (C, D) and E18.5 (E). Note Ltbp1L-LacZ appears as microlumen form within the mammary sprout (B, D, E arrows). Ltbp1L-LacZ is absent from the bulbous multilayered tips (E, arrowhead). Ltbp1L-LacZ is sustained in the mammary mesenchyme (A, B) and developing smooth muscle cells of the nipple areola (C, D). Scale bars represent distance in microns.

\section{Ltbp $1 L$ activity is dramatically upregulated during involution}

During lactation luminal cells of both ducts and alveoli undergo secretory differentiation. Ltbp1L-LacZ expression was undetectable in whole mounts and sections at this stage (Figure 10A, B) consistent with the relative diminishment of Ltbp1 mRNA expression at this stage in qRT-PCR analysis (Figure 7A, B). Milk stasis and ductal distension trigger an initial phase of involution involving cell death that is reversible if suckling resumes [37,52]. After $48 \mathrm{~h}$, however, involution proceeds irreversibly with collapse and removal of transient alveolar and side-branch structures. Throughout this process the permanent ductal system and resident stem cells are protected from destruction. Within 24 hours of pup weaning Ltbp1L-LacZ expression appeared along the main ducts and distended primary side branches (Figure 10C, D). In sections, the reporter expression appeared in a discontinuous pattern within a subset of luminal cells (Figure 10D) and was absent from alveoli, which remained morphologically distended. By $72 \mathrm{~h}$, as the alveoli collapsed and were undergoing clearance, Ltbp1LLacZ became robustly expressed within remaining luminal epithelia (Figure 10E, F). This sharp increase in LTBP1 expression around the transition to irreversible involution was confirmed by qRT-PCR where Ltbp1, $1 \mathrm{~L}$ and $1 \mathrm{~S}$ mRNA peaked at $72 \mathrm{~h}$ (Figure 7A, B). Collectively these results show that both forms of $L t b p 1$ are transcriptionally regulated throughout mammary development in a highly dynamic temporal and spatial manner and are maximal during involution.

\section{Ltbp1 and elastin encase the mammary ductal system}

Having identified the spatial pattern of $L t b p 1 L$ promoter activity and expression levels of both Ltbp1 mRNAs we next sought to determine the localization of the secreted Ltbp1L protein. We first examined sections of involuting glands by immunofluorescence and found Ltbp1L localized in microfibrillar strands surrounding ducts (Figure 10G). Resorcin-fuchsin detected elastic fibers in a similar periductal organization (Figure 10H). We next examined Ltbp1L 

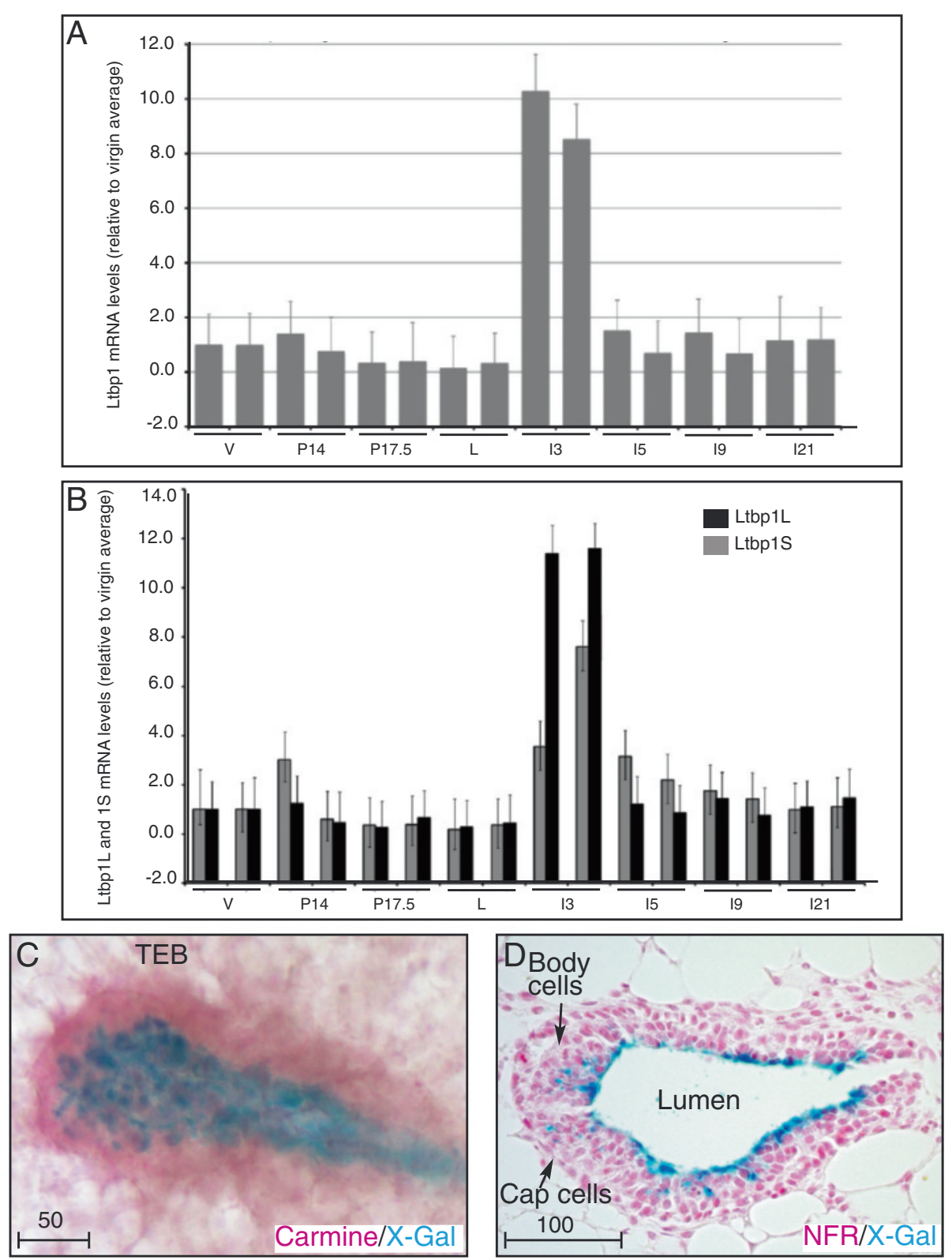

Figure 7 Latent TGF $\beta$ binding protein (Ltbp) 1 L expression in the postnatal mammary gland. (A) Ltbp1 mRNA expression is highly elevated during early involution peaking 3 days after forced pup weaning. (B) Ltbp1L (black bars) and Ltbp1S (gray bars) are most abundant during early involution day 3. Total RNA from mammary gland tissues, harvested from various developmental time points (12-week virgin (V), 14 days pregnant (P14) and 17.5 days pregnant (P17.5), lactating (L), involution days 3 (I3), 5 (I5), 9 (I9) and 21 (I21)), was reverse transcribed and subjected to qRT-PCR. Ltbp1 (A) mRNA levels as well as those of Ltbp1L and Ltbp1S isoforms (B) were normalized to $\beta 2$-microglobulin expression and plotted as levels relative to tissue from 12-week-old virgins. Error bars indicate standard deviation of the cycle threshold $(C t)$ values $(n=4)$. $m R N A$ levels from two representative mouse samples for each time point are shown on the graphs. (C, D) Ltbp1L-LacZ (blue stain) expression in cells bordering the lumen of the terminal end bud (TEB). (C) In carmine-5-bromo-4-chloro-3-indolyl- $\beta$-D-galactoside (X-Gal)-stained whole mounts, Ltbp1L-LacZ localizes to the internal portion of TEB and is surrounded by non-expressing cap and body cell layers. Note the punctate appearance of X-Gal staining demonstrating that Ltbp1L-LacZ is in a subset of luminal cells. (D) Sections of the same 5-week-old virgin stained with nuclear fast red shows Ltbp1L-LacZ expression in cells bordering the lumen. Scale bars represent distance in microns.

and elastin organization at earlier stages (Figure 11). In pubertal glands SMA antibodies detected the basal cell layer of ducts (Figure 11A, B) but was absent from the contiguous cap cell layer of TEBs. Ltbp1 antibodies showed extensive regions of colocalization with SMA-positive basal cells along ducts but was also absent from the SMA-negative cap cell 

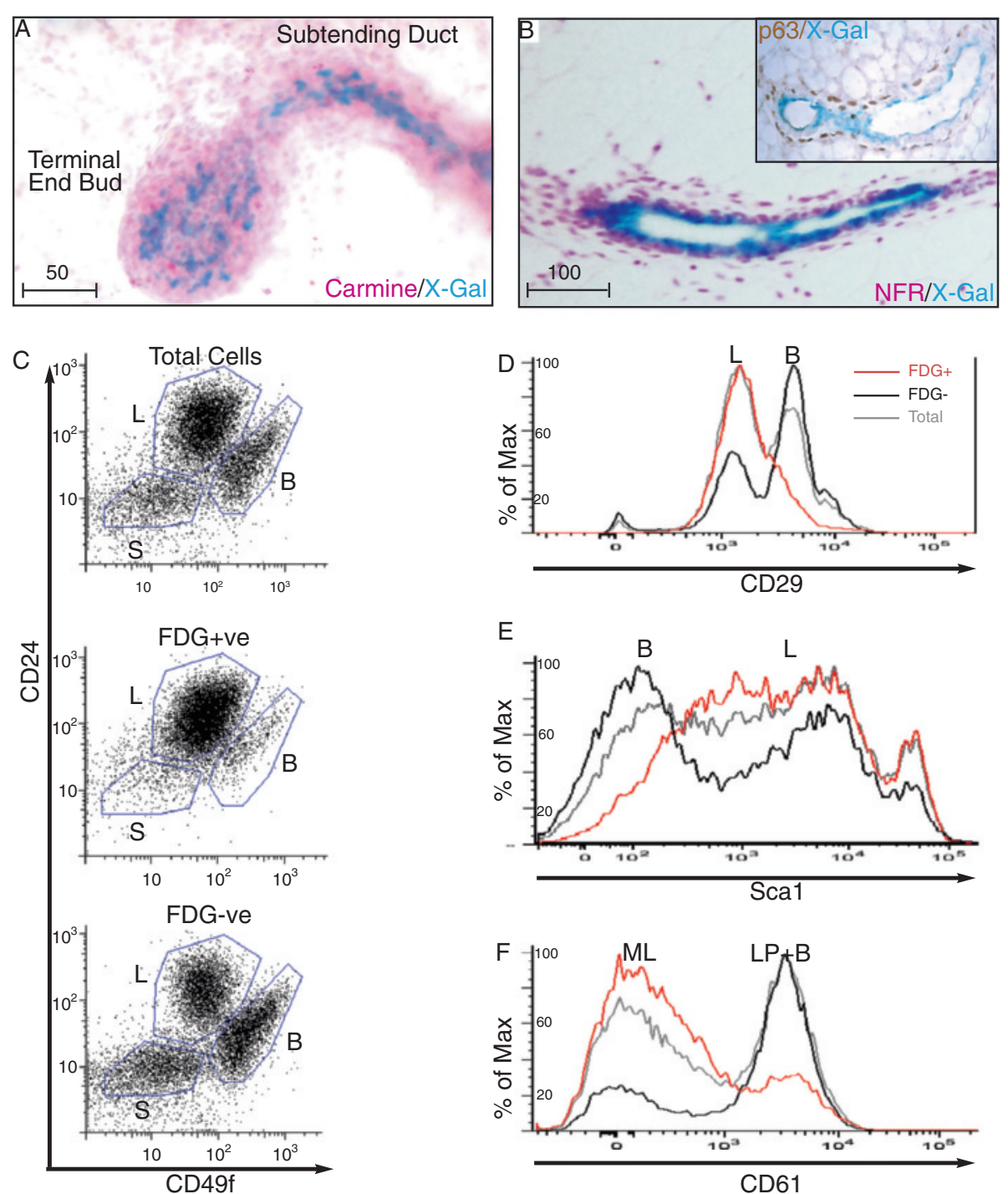

Figure 8 A major subset of ductal luminal cells show Ltbp1L activity. (A) Carmine/5-bromo-4-chloro-3-indolyl- $\beta$-D-galactoside (X-Gal)-stained whole mount of the terminal end bud, (B) nuclear fast red-stained section of the mature duct show Ltbp1L-LacZ expression in luminal cells, basal cells are visualized by immunohistochemcal detection of p63 (inset). Flow cytometry gating for FDG-Gal ${ }^{+}\left(\mathrm{Ltbp} 1 \mathrm{~L}-\mathrm{LacZ}^{+}\right.$cells enriches for the luminal CD24+CD49 ${ }^{\mathrm{LO}}$ compartment (C, top panel). Ltbp1L-LacZ marks $65 \%$ of total luminal cells (C, middle panel), and $35 \%$ of luminal cells are Ltbp1L-LacZ-negative (C, bottom panel). Gates represent stromal $S$, luminal $L$, and basal B populations from two mature virgin mice. (D-F) Histograms show Ltbp1L-LacZ -positive cells (red) are CD29 $9^{\mathrm{LO}}$ (D), Sca- ${ }^{\mathrm{HI}}(\mathbf{E})$ and $C D 61^{\mathrm{LO}}(\mathbf{F})$. Data represents $\mathrm{n}=2$ replicates for all experiments. Peaks represent luminal $L$, basal $B$, mature luminal $M L$ and luminal progenitors $L P$. Scale bars represent distance in microns.

layer of TEBs indicating that Ltbp1 is deposited in close apposition to differentiated myoepithelial cells (Figure 11A-B). Weak Ltbp1 staining was seen in a few body cells of the TEB. The ductal system was also encased by a thick mesh of elastic fibers detected by anti-tropoelastin (Figure 11C). The elastic fibers, however, localized more distantly from the basal cell layer than Ltbp1. In glands from pregnant mice, Ltbp1 surrounded both the permanent ductal system and temporary side branches but was absent from alveolar clusters (Figure 11D). In contrast elastic fibers were restricted to the permanent ductal system (Figure 11E).

\section{Discussion}

The importance of TGF $\beta$ signaling for mammary physiology and pathology has been well documented however the factors that regulate TGF $\beta$ presentation and activation are less well-understood [53]. Although LTBPs determine the spatial deposition of latent TGF $\beta$ and thus define the coordinates for its subsequent activation, surprisingly nothing is known about them in normal mammary gland. Here we show that $L t b p 1$ is dynamically and focally regulated throughout mammary development. The major findings of our study are that 1) Within the mammary epithelium, 

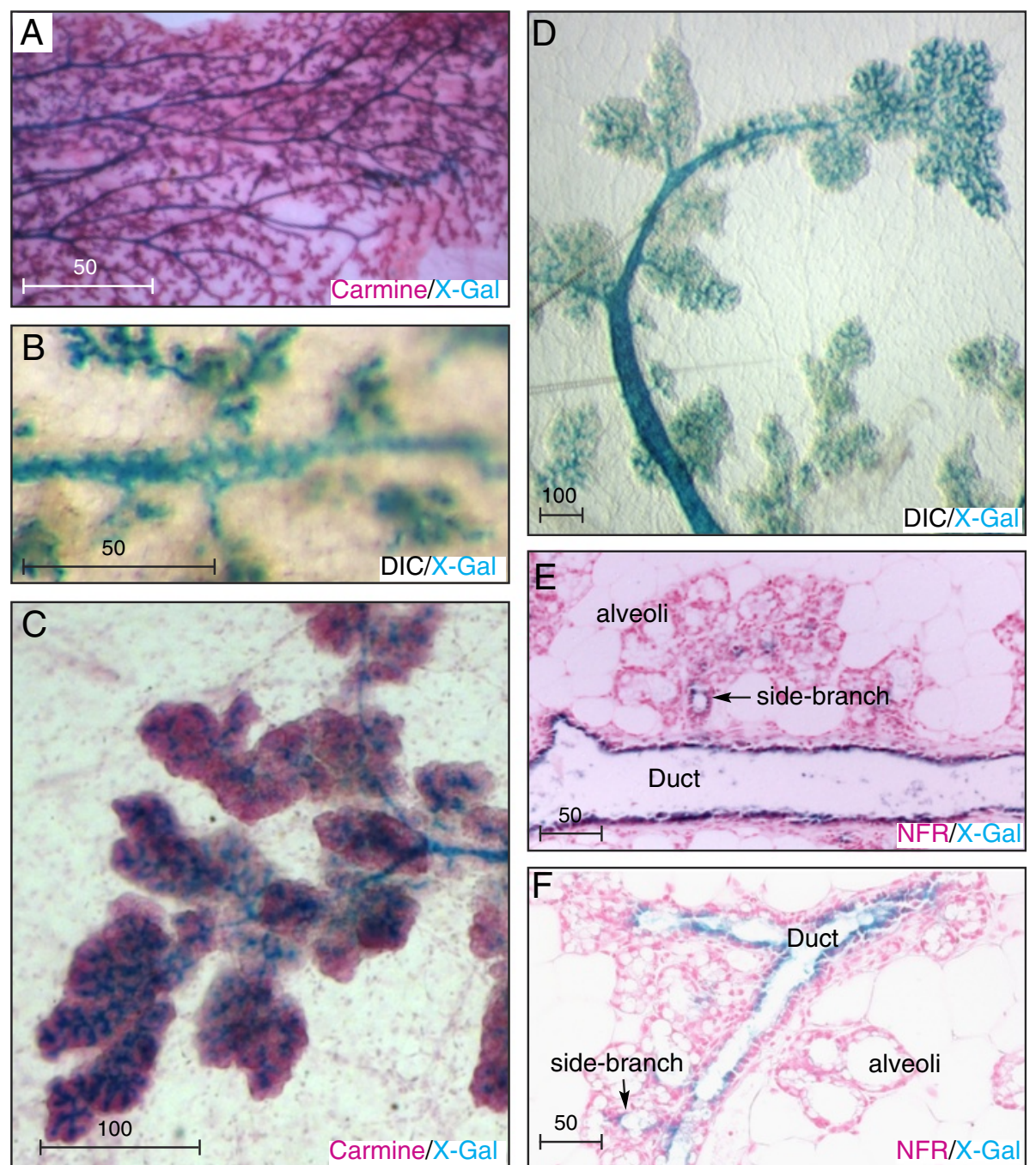

Figure 9 Latent TGF $\beta$ binding protein (Ltbp) $1 L$ is silent in secretory alveoli during pregnancy. (A-D) The 5-bromo-4-chloro-3-indolyl- $\beta$-Dgalactoside (X-Gal)-stained whole mounts show Ltbp1L-LacZ (blue stain) is expressed in ducts and side branches at all stages of pregnancy, but absent from alveoli. (A) Carmine/X-Gal-stained whole mount P13.5. (B) Ltbp1L-LacZ is expressed in a reticular staining pattern demarcating a subset of ductal cells. (C) Carmine/X-Gal-stained whole mount P14.5 (D) X-Gal-stained whole mount P14.5. (E, F) nuclear fast red(NFR)/X-Gal-stained sections P16.5 show Ltbp1L-LacZ is expressed in ducts but not in adjacent alveoli. Scale bars represent distance in microns.

Ltbp1L is transcribed exclusively by ductal luminal cells and distinguishes them from the alveolar luminal lineage; 2) Ltbp1 protein and elastic fibers exclusively encase the ductal system; 3) Ltbp $1 L$ and $1 S$ are upregulated during involution, a developmental window linked to high risk for breast cancer promotion; and 4) Ltbp $1 L$ is induced in mammary mesenchyme and sustained in the smoothmuscle cells of the nipple sphincter.

\section{Ltbp $1 L$ is induced in embryonic mammary mesenchyme and persists in nipple sphincter cells}

Ltbp1L-LacZ is first expressed in an arc around the forelimb. This pattern is intriguing in light of reports that mammary precursors destined for placodes 1 to $3 \mathrm{mi}$ grate along a similar path [47]. It is well known that
TGF $\beta$ signaling promotes EMT and motogenesis. Thus, $L t b p 1 L$ expression may designate a migratory route and potentially stimulate ectodermal cell migration by presenting a focal source of TGF $\beta$. Ltbp $1 L$ is next upregulated in the specialized mammary mesenchyme, which plays a pivotal role in inducing mammary morphogenesis and specifying the embryonic nipple and areola [49]. To date there have been no reports of TGF $\beta$ involvement in these inductive processes, although other members of the TGF $\beta$ family, such as bone morphogenic protein (BMP)4, are known to play critical roles [54,55]. We find that the expression of mammary mesenchymal markers remains unperturbed and embryonic mammary development proceeds normally in $L t b p 1 L^{l z / l z}$ embryos, indicating that $L t b p 1 L$ is not essential for mammary 

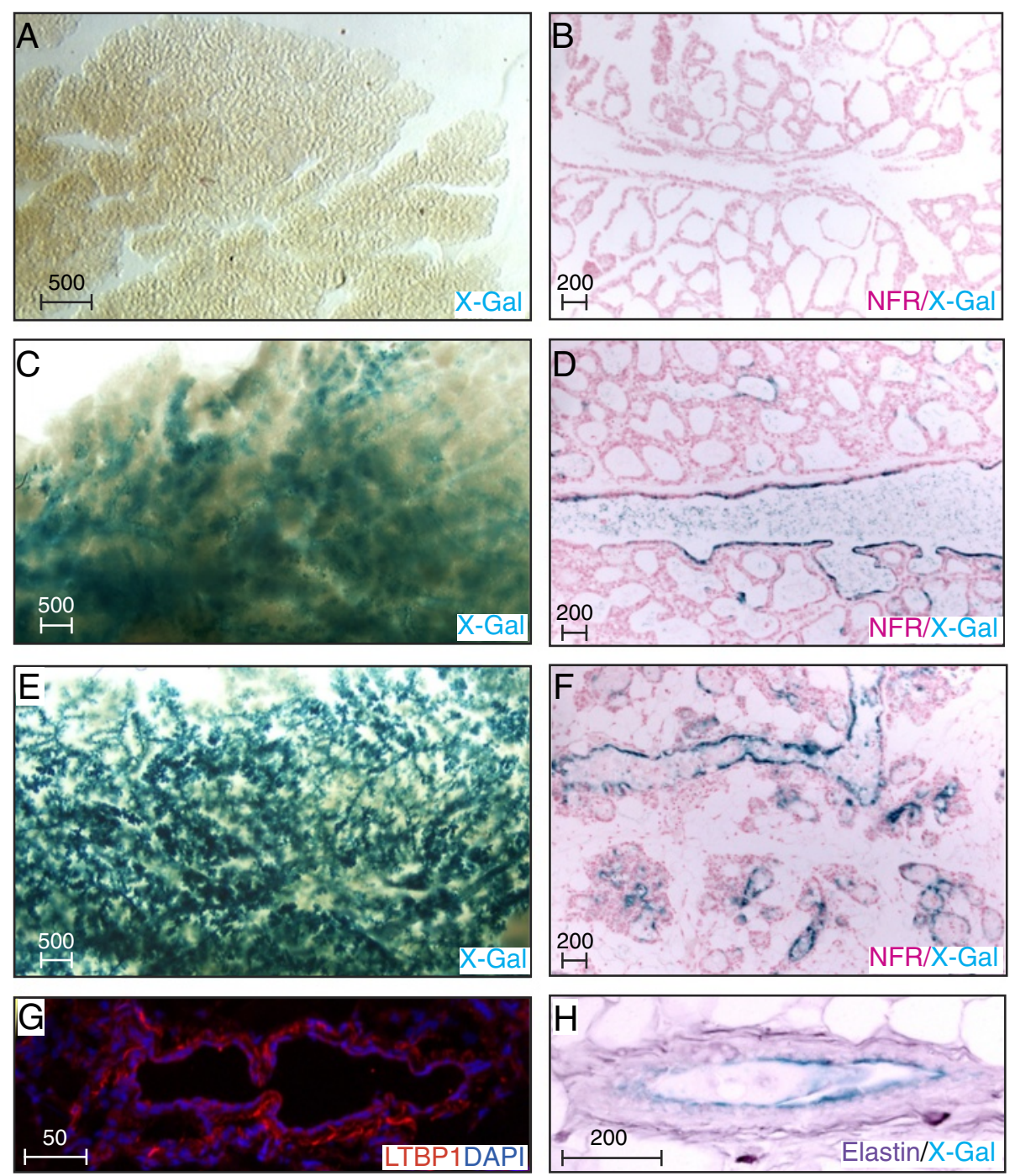

Figure 10 Modulation of latent TGF $\beta$ binding protein (Ltbp)1L-LacZ expression during involution. (A, C, E) The 5-bromo-4-chloro-3indolyl- $\beta$-D-galactoside (X-Gal)-stained whole mounts and (B, D, F) nuclear fast red (NFR)-stained sections of lactating (A, B), and involuting glands removed $24 \mathrm{~h}(\mathbf{C}, \mathbf{D})$ and $72 \mathrm{~h}(\mathbf{E}, \mathbf{F})$ after forced pup weaning. (G) Immunofluorescent detection of frozen mammary glands isolated from mice at involution day 5 using anti-LTBP1 (red) and counterstained with 4',6-diamidino-2-phenylindole (DAPI) (blue) to detect nuclei. (H) Elastic fibers (purple), identified by resorcin-fuchsin staining, on X-Gal-stained paraffin-embedded sections of mammary gland harvested from mice at involution day 21 shows periductal arrangement of fibrils encasing the permanent duct. Scale bars represent distance in microns.

mesenchyme specification or inductive function. These results do not, however, preclude the possibility that the products of $L t b p 1 S$, which is expressed from an independent promoter, or other $L t b p$ genes may compensate [56]. Alternatively Ltbp1L may function at later stages in the differentiation of these cell types. Ltbp1L-LacZ expression persists within smooth muscle cells aligned in radial arrays under the areola, which facilitate nipple projection and regulate the nipple sphincter during milk let-down. There have been no studies on TGF $\beta$ in the nipple, however, misexpression of Wnt5a, a target gene of TGF $\beta$, has been shown to impair milk ejection, supporting the concept that specific levels of TGF $\beta$ signaling may be critical for nipple function [57]. We also observe strong Ltbp1L-LacZ expression in myofibroblasts during mid-pregnancy when the stroma synthesizes elastin to provide structural support for the lactiferous duct [58]. Whether Ltbp1L functions to reinforce the surrounding elastic fibers, and/or serves in a mechanosensory capacity between TGF $\beta$ signaling and the establishment of the unique nipple stroma, remains to be determined.

\section{Ltbp1 and ductal cell fate}

Ltbp $1 L$ activity is a consistent marker of the ductal luminal lineage, appearing in the embryo at the first sign 

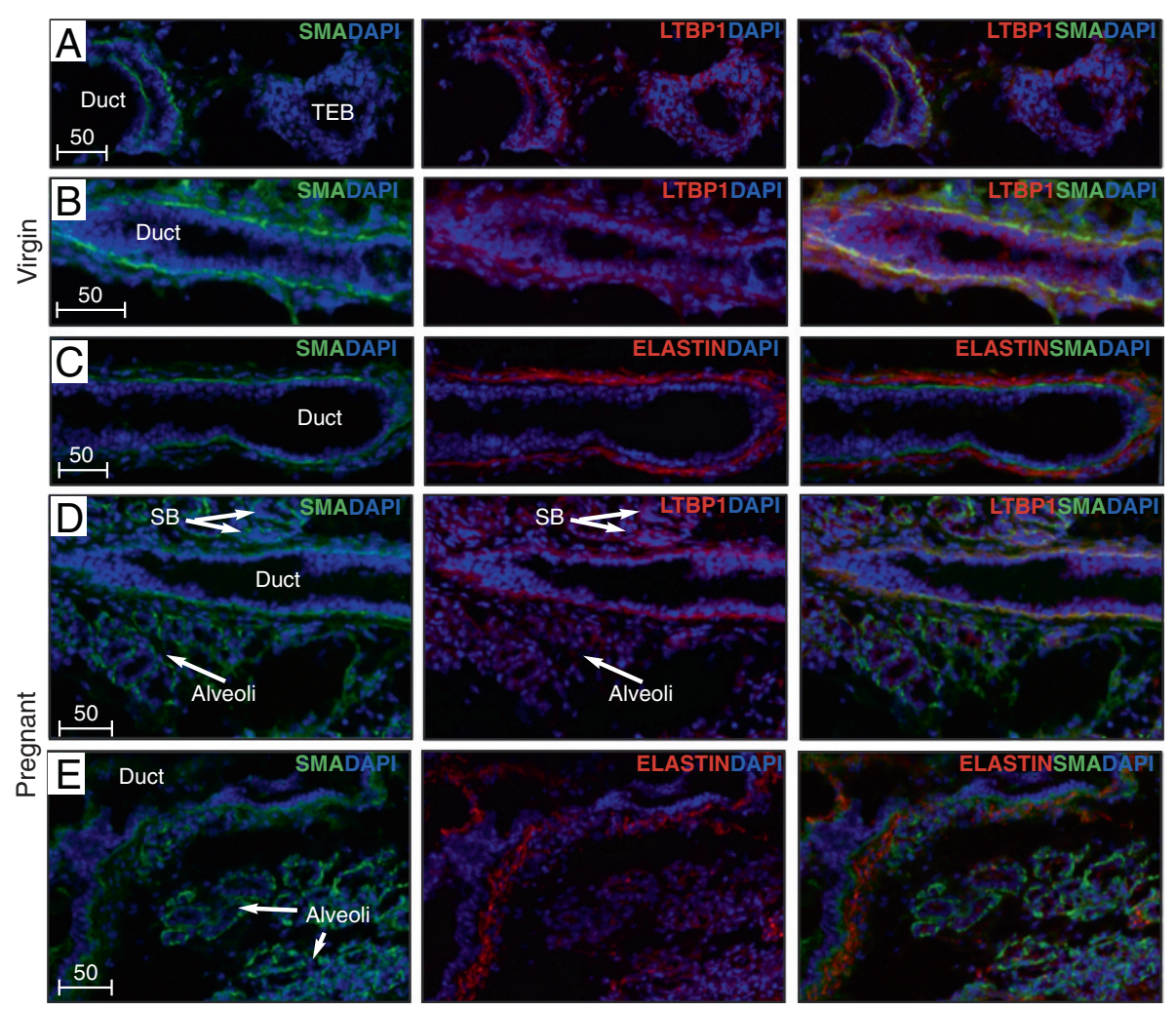

Figure 11 Localization of latent TGF $\beta$ binding protein (Ltbp)1 and elastin in the pubertal and pregnant mammary gland.

Immunofluorescent detection of Ltbp1 (A, B and D), elastin (C, E) and smooth-muscle actin (SMA) (A-E) in frozen sections of mammary glands isolated from 6-week-old pubertal (A-C) and 14.5-day pregnant mice (D, E). Anti-SMA detected by Alexa-488 secondary antibodies (green) localized basal myoepithelial cells of mature ducts but not cap cells of the terminal end bud (TEB) and robustly stained basal cells of alveoli. Anti-Ltbp1 detected by Cy3-coupled secondary antibodies (red in center panels) in virgin (A, B) and pregnant glands (D) detected Ltbp1 deposited in close apposition to the SMA-positive basal cell layer (yellow in right merged panel). In contrast the cap cell layer that surrounds the TEB was negative with both anti-SMA and anti-Ltbp1 antibodies. Anti-tropoelastin detected by Cy3 coupled secondary antibodies (red in center and right panels) in virgin (C) and pregnant (E) glands detects elastic fibers surrounding the basal layer. Both Ltbp1 and elastic fibers are excluded from alveolar clusters. Frozen sections were viewed under a Carl Zeiss Confocal LSM510 microscope at 20x magnification and images were acquired using Zen Software version 2010. Scale bars represent distance in microns. DAPI, 4',6-diamidino-2-phenylindole.

of ductal canalization. This specificity is maintained throughout pubertal development and pregnancy where it serves as a rare marker distinguishing ductal from alveolar luminal cells. Transplantation studies have suggested that ductal and alveolar progenitors are distinct, but little is known about differences between mature ductal and alveolar luminal cell-types [59]. $L t b p 1 L$ is active in approximately $65 \%$ of luminal cells but silent within the inner body cells of the TEB, which are thought to be a proliferative progenitor population. It is upregulated within mature $\mathrm{CD}^{-} 1^{-} \mathrm{Scal}^{+}$cells in the subtending duct and within a small subpopulation of CD $61^{+}$luminal progenitors, which we speculate may generate side branches during pregnancy. Previous studies have implicated TGF $\beta$ signaling in suppressing proliferation of luminal populations and maintaining the potency of basal stem cell populations $[34,36,60]$. Our results show that Ltbp1 protein is deposited in close apposition to basal cells encasing the ductal system and thereby positioning TGF $\beta$ to carry out these functions.

\section{Ltbp1 in the physiology of ductal dilation and distension}

The appearance of Ltbp1L-LacZ expression coincident with lumen formation in the embryonic mammary rudiment and in the pubertal TEB suggests Ltbp1 may position TGF $\beta$ to generate lumen by inducing apoptosis [61]. TGF $\beta$ is a well-known pro-apoptotic cytokine and multiple studies have demonstrated a role for apoptotic factors in lumen formation in vitro and in vivo [34,37]. However the periductal restriction of Ltbp1 protein in close association with elastic fibers makes this function unlikely and moreover indicates that they participate in some ductal versus alveolar specific process. A distinguishing feature of ducts is that their lumen remain open at all times. Whether Ltbp1 serves to physically support the open ducts by reinforcing their elastic fiber encasement and/or positions TGF $\beta$ to monitor ductal 
lumenal diameter in a mechanosensory fashion remains to be determined.

\section{Ltbp $1 L$ is silenced during lactation and dramatically induced during involution}

The most dramatic changes in Ltbp 1 activity occurred with the onset and cessation of lactation. Ltbp1, 1L and 1S mRNA were undetectable during lactation, and Ltbp1L-LacZ expression was lost even from the ducts as the entire epithelium assumed a secretory phenotype and the lumen became engorged with milk. This loss of $L t b p 1 L$ and $1 \mathrm{~S}$ expression coincides with a change in the trafficking of latent TGF $\beta$ from basolateral secretion as a large latent complex destined for incorporation into the ECM in an Ltbp-dependent manner to apical secretion of small latent complex into milk, which functions to promote IgA production and induce oral tolerance in the newborn [62].

$L t b p 1 L$ is dramatically induced during involution. Involution is a biphasic event, marked by distinct biological processes. For up to $48 \mathrm{~h}$ after weaning the process is reversible and characterized by alveolar apoptosis. After this point it becomes irreversible, as protease-mediated matrix remodeling leads to alveolar collapse and rebuilding of the ECM, to return the gland to a virgin-like state [63]. Teatsealing experiments have shown that ductal distension triggers involution even in the presence of circulating lactogenic hormones, highlighting the role of local factors [37]. Our results show that Ltbp $1 L$ and $1 S$ are induced within $24 \mathrm{~h}$ and peak at day 3 of involution, remaining elevated for some days. This pattern is similar to that reported for TGF $\beta 3$ in several microarray studies $[64,65]$. TGF $\beta 3$ is upregulated 6 -fold within $3 \mathrm{~h}$ of weaning and has been implicated as a local factor triggering alveolar apoptosis, however, the mechanism for its activation has not been studied [37]. Whether $L t b p 1$ is expressed early enough to facilitate TGF 33 's role in apoptosis remains to be determined. The peak of $L t b p 1$ and TGF $\beta 3$ induction correlates with the transition to the irreversible stage of involution, suggesting that elevated TGF $\beta$ signaling may contribute to this transition. Little is known about the role of TGF $\beta 3$ in later involution, though it has been hypothesized to promote fibroblast migration and ECM generation based on the upregulation of wound healing and ECM genes that are targets of TGF $\beta$ signaling during this phase $[17,63,65]$. Alternatively, the localization of Ltbp1 protein along ducts suggests it may function to protect the permanent ductal system and its ductal stem cells from destruction by integrating integrin and TGF $\beta$ signaling, which promote cell survival and stem cell potency, respectively [66]. Lastly, our finding that Ltbp1 expression is dramatically elevated during involution, when taken collectively with the fact that $L T B P 1$ appears in two metastatic signatures $[5,6]$ and regulates TGF $\beta$, a factor inducing EMT, suggests that LTBP1 may be a prometastatic element in pregnancy-associated breast cancer $(\mathrm{PABC})$. Detected postpartum, PABC is highly aggressive and this feature is thought to result from the action of prometastatic factors in the microenvironment of involuting glands [67]. Thus LTBP1 levels may be worthy of investigation as a risk factor.

\section{Conclusions}

In conclusion, our results establish that $L t b p 1$ is dynamically regulated during mammary development. The pattern of $L t b p 1 L$ activity and Ltbp1 protein localization suggest roles in reinforcing elastic support and mechanosensory feedback for mammary ducts and nipple. Currently nothing is known of the role of this important TGF $\beta$ regulator in human breast. Its elevation during involution suggests LTBP1 is worthy of further investigation as a prometastatic candidate in PABC.

\section{Abbreviations}

AR: Androgen receptor; BAC: Bacterial artificial chromosome; BMP: Bone morphogenetic protein; Bp: Base pairs; CD: Cluster of differentiation; DAPI: 4',6-diamidino-2-phenylindole; ECM: Extracellular matrix;

EDTA: Ethylenediaminetetraacetic acid; EGF: Epidermal growth factor; EMT: Epithelial to mesenchymal transition; ER: Estrogen receptor; ES: Embryonic stem; FAM: 6-carboxyfluorescein (FAM); Fb: Fibrillin;

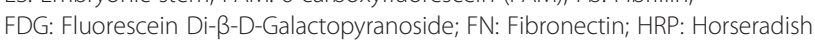
peroxidase; IHC: Immunohistochemistry; LAP: Latency-associated propeptide; Lef1: Lymphoid enhancer-binding factor 1; LLC: Large latent complex; LTBP: Latent TGF $\beta$ binding protein; MGB: Dihydrocyclopyrroloindole tripeptide minor groove binder; NFR: Nuclear fast red; PABC: Pregnancy-associated breast cancer; PBS: Phosphate buffered saline; PFA: Paraformaldehyde; qRT-PCR: Quantitative reverse transcriptase-polymerase chain reaction; RER: Rough endoplasmic reticulum; RGD: Arginine-glycine-aspartic acid; Sca1: Stem cell antigen 1; SLC: Small latent complex; SMA: Smooth muscle actin; SP: Signal peptide; TEB: Terminal end bud; TGF $\beta$ : Transforming growth factor $\beta$; TGF- $\beta R$ : Transforming growth factor $\beta$ Receptor; X-Gal: 5-bromo4-chloro-3-indolyl- $\beta$-D-galactoside.

\section{Competing interests}

The authors declare that they have no competing interests.

\section{Authors' contributions}

AC, JS and AP performed all the experiments in the manuscript (including characterization of Ltbp1 promoter activity throughout mammary development, isolation of RNA from various stages of the postnatal mammary gland for qRT-PCR analysis, flow cytometric analysis of postnatal mammary gland to define ductal luminal populations within the postnatal mammary gland, characterization of Ltbp1 protein expression in virgin, pregnant and involuting mice by immunofluorescence and of elastic fibers by immunofluorescence and resorcin-fuchsin staining), analyzed the data and drafted the manuscript. MH performed the initial characterization of Ltbp1L-LacZ expression on whole-mount embryos at early embryonic stages (E10.5 to E14.5). GD carried out the qRT-PCR amplification of Ltbp 1 and its isoforms $L t b p 1 L$ and $L t b p 1 S$ and analyzed their expression levels in the postnatal mammary gland. DF engineered the original $L t b p 1 L^{\mid z /+}$ mouse by targeted insertional mutagenesis and analyzed the expression levels of Ltbp 1, Ltbp $1 L$ and Ltbp $1 S$ in the postnatal mammary gland. PC conceived of the study, participated in the design of all experiments, coordinated and drafted the manuscript. All authors read and approved the final manuscript.

\section{Acknowledgements}

We thank Drs Daniel Rifkin (NYUSOM), Carl-Henrik Heldin (Uppsala University, Sweden) and Lynn Sakai (Portland Shriners Research Center, Portland, OR) for LTBP reagents. Our colleagues John Munger, Matthias Kugler and Mary Helen Barcellos-Hoff provided valuable comments on the manuscript. We also 
thank Peter Lopez of the NYU Cancer Institute Flow Cytometry and Cell Sorting Center, Drs Ram Dasgupta and Sujash Chatterjee for their expertise and help with confocal imaging, Alejo Mujica for the design of a TaqMan qRT-PCR assay specific for the short form of the Ltbp1 mRNA and Lakeisha Esau, Lisa Koetz, Nikhil Sharma and Cassandra Williams provided technical assistance with experiments. This work was supported by DOD-BC123572 and $\mathrm{NIH}-\mathrm{CA} 129905$ awarded to PC, postdoctoral fellowship DOD-BC112418 awarded to AC, NIH-T32-GM66704-8 training fellowship to JS and NIH training fellowship F31CA130137 awarded to AP. Additionally this work was supported in part by Grant 5P30CA016087-33 from NCI (Flow Cytometry Core New York University (NYU) Cancer Institute). The funders had no role in study design, data collection and analysis, decision to publish, or preparation of the manuscript.

\section{Author details}

'Department of Cell Biology, New York University School of Medicine, New York, NY, USA. ${ }^{2}$ The Ronald O Perelman Department of Dermatology, New York University School of Medicine, 550 First Ave, New York, NY 10016, USA ${ }^{3}$ Regeneron Pharmaceuticals, 777 Old Saw Mill River Rd, Tarrytown, NY 10591, USA.

Received: 18 March 2013 Accepted: 31 October 2013

Published: 21 November 2013

\section{References}

1. Chandramouli A, Simundza J, Pinderhughes A, Cowin P: Choreographing metastasis to the tune of LTBP. J Mammary Gland Biol Neoplasia 2011, 16:67-80.

2. Ali M, McKibbin M, Booth A, Parry DA, Jain P, Riazuddin SA, Hejtmancik JF, Khan SN, Firasat S, Shires M, Gilmour DF, Towns K, Murphy AL, Azmanov D, Tournev I, Cherninkova S, Jafri H, Raashid Y, Toomes C, Craig J, Mackey DA, Kalaydjieva L, Riazuddin S, Inglehearn, CF: Null mutations in LTBP2 cause primary congenital glaucoma. Am J Hum Genet 2009, 84:664-671.

3. Noor A, Windpassinger C, Vitcu I, Orlic M, Rafiq MA, Khalid M, Malik MN, Ayub M, Alman B, Vincent JB: Oligodontia is caused by mutation in LTBP3, the gene encoding latent TGF-beta binding protein 3. Am J Hum Genet 2009, 84:519-523.

4. Urban Z, Hucthagowder V, Schurmann N, Todorovic V, Zilberberg L, Choi J, Sens C, Brown CW, Clark RD, Holland KE, Marble M, Sakai LY, Dabovic B, Rifkin DB, Davis EC: Mutations in LTBP4 cause a syndrome of impaired pulmonary, gastrointestinal, genitourinary, musculoskeletal, and dermal development. Am J Hum Genet 2009, 85:593-605.

5. Bos PD, Zhang XH, Nadal C, Shu W, Gomis RR, Nguyen DX, Minn AJ, van de Vijver MJ, Gerald WL, Foekens JA, Massague J: Genes that mediate breast cancer metastasis to the brain. Nature 2009, 459:1005-1009.

6. Minn AJ, Gupta GP, Padua D, Bos P, Nguyen DX, Nuyten D, Kreike B, Zhang $Y$, Wang Y, Ishwaran H, Foekens JA, van de Vijver MJ, Massague J: Lung metastasis genes couple breast tumor size and metastatic spread. Proc Natl Acad Sci USA 2007, 104:6740-6745.

7. Saharinen J, Hyytiainen M, Taipale J, Keski-Oja J: Latent transforming growth factor-beta binding proteins (LTBPs)-structural extracellular matrix proteins for targeting TGF-beta action. Cytokine Growth Factor Rev 1999, 10:99-117.

8. Zilberberg L, Todorovic V, Dabovic B, Horiguchi M, Courousse T, Sakai LY, Rifkin DB: Specificity of latent TGF-beta binding protein (LTBP) incorporation into matrix: role of fibrillins and fibronectin. J Cell Physiol 2012, 227:3828-3836

9. Sterner-Kock A, Thorey IS, Koli K, Wempe F, Otte J, Bangsow T, Kuhlmeier K Kirchner T, Jin S, Keski-Oja J, von Melchner H: Disruption of the gene encoding the latent transforming growth factor-beta binding protein 4 (LTBP-4) causes abnormal lung development, cardiomyopathy, and colorectal cancer. Genes Dev 2002, 16:2264-2273.

10. Dabovic B, Chen Y, Choi J, Vassallo M, Dietz HC, Ramirez F, von Melchner H, Davis EC, Rifkin DB: Dual functions for LTBP in lung development: LTBP-4 independently modulates elastogenesis and TGF-beta activity. J Cell Physiol 2009, 219:14-22.

11. Miyazono K, Hellman U, Wernstedt C, Heldin CH: Latent high molecular weight complex of transforming growth factor beta 1, Purification from human platelets and structural characterization. J Biol Chem 1988, 263:6407-6415.
12. Taipale J, Saharinen J, Hedman K, Keski-Oja J: Latent transforming growth factor-beta 1 and its binding protein are components of extracellular matrix microfibrils. J Histochem Cytochem 1996, 44:875-889.

13. Annes JP, Chen Y, Munger JS, Rifkin DB: Integrin alphaVbeta6-mediated activation of latent TGF-beta requires the latent TGF-beta binding protein-1. J Cell Biol 2004, 165:723-734.

14. Munger JS, Huang X, Kawakatsu H, Griffiths MJ, Dalton SL, Wu J, Pittet JF, Kaminski N, Garat C, Matthay MA, et al: The integrin alpha $v$ beta 6 binds and activates latent TGF beta 1: a mechanism for regulating pulmonary inflammation and fibrosis. Cell 1999, 96:319-328.

15. Munger JS, Sheppard D: Cross talk among TGF-beta signaling pathways, integrins, and the extracellular matrix. Cold Spring Harb Perspect Biol 2011, 3:a005017.

16. Wipff PJ, Rifkin DB, Meister JJ, Hinz B: Myofibroblast contraction activates latent TGF-beta1 from the extracellular matrix. J Cell Biol 2007, 179:1311-1323.

17. Flanders KC, Wakefield LM: Transforming growth factor-(beta)s and mammary gland involution; functional roles and implications for cancer progression. J Mammary Gland Biol Neoplasia 2009, 14:131-144.

18. Todorovic V, Rifkin DB: LTBPs, more than just an escort service. J Cell Biochem 2012, 113:410-418.

19. Drews F, Knobel S, Moser M, Muhlack KG, Mohren S, Stoll C, Bosio A, Gressner AM, Weiskirchen R: Disruption of the latent transforming growth factor-beta binding protein-1 gene causes alteration in facial structure and influences TGF-beta bioavailability. Biochimica Et Biophysica Acta 2008, 1783:34-48.

20. Todorovic V, Frendewey D, Gutstein DE, Chen Y, Freyer L, Finnegan E, Liu F, Murphy A, Valenzuela D, Yancopoulos G, Rifkin DB: Long form of latent TGF-beta binding protein 1 (Ltbp1L) is essential for cardiac outflow tract septation and remodeling. Development 2007, 134:3723-3732.

21. Shipley JM, Mecham RP, Maus E, Bonadio J, Rosenbloom J, McCarthy RT, Baumann ML, Frankfater C, Segade F, Shapiro SD: Developmental expression of latent transforming growth factor beta binding protein 2 and its requirement early in mouse development. Mol Cell Biol 2000, 20:4879-4887.

22. Dabovic B, Chen Y, Colarossi C, Obata H, Zambuto L, Perle MA, Rifkin DB: Bone abnormalities in latent TGF-[beta] binding protein (Ltbp)-3-null mice indicate a role for Ltbp-3 in modulating TGF-[beta] bioavailability. J Cell Biol 2002, 156:227-232.

23. Dabovic B, Chen Y, Colarossi C, Zambuto L, Obata H, Rifkin DB: Bone defects in latent TGF-beta binding protein (Ltbp)-3 null mice; a role for Ltbp in TGF-beta presentation. J Endocrinol 2002, 175:129-141.

24. Noda K, Dabovic B, Takagi K, Inoue T, Horiguchi M, Hirai M, Fujikawa Y, Akama TO, Kusumoto K, Zilberberg L, Sakai LY, Koli K, Naitoh M, von Melchner H, Suziki S, Rifkin DB, Nakamura T: Latent TGF-beta binding protein 4 promotes elastic fiber assembly by interacting with fibulin-5. Proc Natl Acad Sci USA 2013, 110:2852-2857.

25. Robinson SD, Silberstein GB, Roberts AB, Flanders KC, Daniel CW: Regulated expression and growth inhibitory effects of transforming growth factor-beta isoforms in mouse mammary gland development. Development 1991, 113:867-878.

26. Roarty K, Serra R: Wnt5a is required for proper mammary gland development and TGF-beta-mediated inhibition of ductal growth. Development 2007, 134:3929-3939.

27. Bierie B, Moses HL: Tumour microenvironment: TGFbeta: the molecular Jekyll and Hyde of cancer. Nat Rev Cancer 2006, 6:506-520.

28. Joseph H, Gorska AE, Sohn P, Moses HL, Serra R: Overexpression of a kinase-deficient transforming growth factor-beta type II receptor in mouse mammary stroma results in increased epithelial branching. Mol Biol Cell 1999, 10:1221-1234.

29. Pierce DF Jr, Johnson MD, Matsui Y, Robinson SD, Gold LI, Purchio AF, Daniel CW, Hogan BL, Moses HL: Inhibition of mammary duct development but not alveolar outgrowth during pregnancy in transgenic mice expressing active TGF-beta 1. Genes Dev 1993, 7:2308-2317.

30. Silberstein GB, Daniel CW: Reversible inhibition of mammary gland growth by transforming growth factor-beta. Science 1987, 237:291-293.

31. Daniel CW, Silberstein GB, Van Horn K, Strickland P, Robinson S: TGF-beta 1-induced inhibition of mouse mammary ductal growth: developmental specificity and characterization. Dev Biol 1989, 135:20-30.

32. Gorska AE, Joseph H, Derynck R, Moses HL, Serra R: Dominant-negative interference of the transforming growth factor beta type II receptor in 
mammary gland epithelium results in alveolar hyperplasia and differentiation in virgin mice. Cell Growth Differ 1998, 9:229-238.

33. Jhappan C, Geiser AG, Kordon EC, Bagheri D, Hennighausen L, Roberts AB, Smith GH, Merlino G: Targeting expression of a transforming growth factor beta 1 transgene to the pregnant mammary gland inhibits alveolar development and lactation. Embo J 1993, 12:1835-1845.

34. Kordon EC, McKnight RA, Jhappan C, Hennighausen L, Merlino G, Smith GH: Ectopic TGF beta 1 expression in the secretory mammary epithelium induces early senescence of the epithelial stem cell population. Dev Biol 1995, 168:47-61.

35. Robinson GW, Smith GH, Gallahan D, Zimmer A, Furth PA, Hennighausen L: Understanding mammary gland development through the imbalanced expression of growth regulators. Dev Dyn 1996, 206:159-168.

36. Ewan KB, Shyamala G, Ravani SA, Tang Y, Akhurst R, Wakefield L, BarcellosHoff $\mathrm{MH}$ : Latent transforming growth factor-beta activation in mammary gland: regulation by ovarian hormones affects ductal and alveolar proliferation. Am J Pathol 2002, 160:2081-2093.

37. Nguyen AV, Pollard JW: Transforming growth factor beta 3 induces cell death during the first stage of mammary gland involution. Development 2000, 127:3107-3118.

38. Pollard JW: Tumour-stromal interactions, Transforming growth factor-beta isoforms and hepatocyte growth factor/scatter factor in mammary gland ductal morphogenesis. Breast Cancer Res 2001, 3:230-237.

39. Barcellos-Hoff MH: Radiation-induced transforming growth factor beta and subsequent extracellular matrix reorganization in murine mammary gland. Cancer Res 1993, 53:3880-3886.

40. Barcellos-Hoff MH, Derynck R, Tsang ML, Weatherbee JA: Transforming growth factor-beta activation in irradiated murine mammary gland. J Clin Invest 1994, 93:892-899.

41. Valenzuela DM, Murphy AJ, Frendewey D, Gale NW, Economides AN, Auerbach W, Poueymirou WT, Adams NC, Rojas J, Yasenchak J, Chernomorsky R, Boucher M, Elsasser AL, Esau L, Zheng J, Griffiths JA, Wang $X$, Su H, Xue Y, Dominguez MG, Noguera I, Torres R, Macdonald LE, Stewart AF, DeChiara TM, Yancopoulos GD: High-throughput engineering of the mouse genome coupled with high-resolution expression analysis. Nat Biotechnol 2003, 21:652-659.

42. Muyrers JP, Zhang Y, Testa G, Stewart AF: Rapid modification of bacterial artificial chromosomes by ET-recombination. Nucleic Acids Res 1999, 27:1555-1557.

43. Miyazono $\mathrm{K}$, Olofsson $\mathrm{A}$, Colosetti $\mathrm{P}$, Heldin $\mathrm{CH}$ : A role of the latent TGF-beta 1-binding protein in the assembly and secretion of TGF-beta 1. Embo J 1991, 10:1091-1101.

44. Isogai Z, Ono RN, Ushiro S, Keene DR, Chen Y, Mazzieri R, Charbonneau NL, Reinhardt DP, Rifkin DB, Sakai LY: Latent transforming growth factor beta-binding protein 1 interacts with fibrillin and is a microfibril-associated protein. J Biol Chem 2003, 278:2750-2757

45. Sheehan C, Hrapchak B: Connective tissue and muscle fiber stain. In Theory and Practice of Histotechnology. 2nd edition. St Louis, MO: C.V. Mosby Co; 1980. p199

46. Cowin P, Wysolmerski J: Molecular mechanisms guiding embryonic mammary gland development. Cold Spring Harbor Perspect Biol 2010, 2:a003251.

47. Cho KW, Kim JY, Song SJ, Farrell E, Eblaghie MC, Kim HJ, Tickle C, Jung HS: Molecular interactions between Tbx3 and Bmp4 and a model for dorsoventral positioning of mammary gland development. Proc Natl Acad Sci USA 2006, 103:16788-16793.

48. Dunbar ME, Dann PR, Robinson GW, Hennighausen L, Zhang JP, Wysolmerski $\mathrm{JJ}$ : Parathyroid hormone-related protein signaling is necessary for sexual dimorphism during embryonic mammary development. Development 1999 126:3485-3493.

49. Foley J, Dann P, Hong J, Cosgrove J, Dreyer B, Rimm D, Dunbar M, Philbrick W, Wysolmerski J: Parathyroid hormone-related protein maintains mammary epithelial fate and triggers nipple skin differentiation during embryonic breast development. Development 2001, 128:513-525.

50. Toyoshima Y, Ohsako S, Nagano R, Matsumoto M, Hidaka S, Nishinakagawa $\mathrm{H}$ : Histological changes in mouse nipple tissue during the reproductive cycle. J Vet Med Sci 1998, 60:405-411.

51. Visvader JE: Keeping abreast of the mammary epithelial hierarchy and breast tumorigenesis. Genes Dev 2009, 23:2563-2577.

52. Wakefield LM, Yang YA, Dukhanina O: Transforming growth factor-beta and breast cancer: Lessons learned from genetically altered mouse models. Breast Cancer Res 2000, 2:100-106.
53. Roberts $A B$, Wakefield $L M$ : The two faces of transforming growth factor beta in carcinogenesis. Proc Natl Acad Sci USA 2003, 100:8621-8623.

54. Hens J, Dann P, Hiremath M, Pan TC, Chodosh L, Wysolmerski J: Analysis of gene expression in PTHrP-/- mammary buds supports a role for BMP signaling and MMP2 in the initiation of ductal morphogenesis. Dev Dyn 2009, 238:2713-2724.

55. Hens JR, Dann P, Zhang JP, Harris S, Robinson GW, Wysolmerski J: BMP4 and PTHrP interact to stimulate ductal outgrowth during embryonic mammary development and to inhibit hair follicle induction. Development 2007, 134:1221-1230.

56. Noguera I, Obata H, Gualandris A, Cowin P, Rifkin DB: Molecular cloning of the mouse Ltbp-1 gene reveals tissue specific expression of alternatively spliced forms. Gene 2003, 308:31-41.

57. Baxley SE, Jiang W, Serra R: Misexpression of wingless-related MMTV integration site $5 \mathrm{~A}$ in mouse mammary gland inhibits the milk ejection response and regulates connexin43 phosphorylation. Biol Reprod 2011 85:907-915.

58. Abdalkhani A, Sellers R, Gent J, Wulitich H, Childress S, Stein B, Boissy RE, Wysolmerski JJ, Foley J: Nipple connective tissue and its development: insights from the K14-PTHrP mouse. Mech Dev 2002, 115:63-77.

59. Chepko G, Smith GH: Mammary epithelial stem cells: our current understanding. J Mammary Gland Biol Neoplasia 1999, 4:35-52.

60. Ewan KB, Oketch-Rabah HA, Ravani SA, Shyamala G, Moses HL, Barcellos-Hoff $\mathrm{MH}$ : Proliferation of estrogen receptor-alpha-positive mammary epithelial cells is restrained by transforming growth factor-beta 1 in adult mice. Am J Pathol 2005, 167:409-417.

61. Mailleux AA, Overholtzer M, Schmelzle T, Bouillet P, Strasser A, Brugge JS: BIM regulates apoptosis during mammary ductal morphogenesis, and its absence reveals alternative cell death mechanisms. Dev Cell 2007 12:221-234

62. Letterio JJ, Geiser AG, Kulkarni AB, Roche NS, Sporn MB, Roberts AB: Maternal rescue of transforming growth factor-beta 1 null mice. Science 1994, 264:1936-1938.

63. Watson CJ, Kreuzaler PA: Remodeling mechanisms of the mammary gland during involution. Int J Dev Biol 2011, 55:757-762.

64. Clarkson RW, Wayland MT, Lee J, Freeman T, Watson CJ: Gene expression profiling of mammary gland development reveals putative roles for death receptors and immune mediators in post-lactational regression. Breast Cancer Res 2004, 6:R92-R109.

65. Clarkson RW, Watson CJ: Microarray analysis of the involution switch. J Mammary Gland Biol Neoplasia 2003, 8:309-319.

66. Salm SN, Burger PE, Coetzee S, Goto K, Moscatelli D, Wilson EL: TGF-\{beta maintains dormancy of prostatic stem cells in the proximal region of ducts. J Cell Biol 2005, 170:81-90.

67. Lyons TR, O'Brien J, Borges VF, Conklin MW, Keely PJ, Eliceiri KW, Marusyk A, Tan AC, Schedin P: Postpartum mammary gland involution drives progression of ductal carcinoma in situ through collagen and COX-2. Nat Med 2011, 17:1109-1115.

\section{doi: $10.1186 / \mathrm{bcr} 3578$}

Cite this article as: Chandramouli et al: $L t b p 1 L$ is focally induced in embryonic mammary mesenchyme, demarcates the ductal luminal lineage and is upregulated during involution. Breast Cancer Research 2013 15:R111.

\section{Submit your next manuscript to BioMed Central and take full advantage of:}

- Convenient online submission

- Thorough peer review

- No space constraints or color figure charges

- Immediate publication on acceptance

- Inclusion in PubMed, CAS, Scopus and Google Scholar

- Research which is freely available for redistribution 